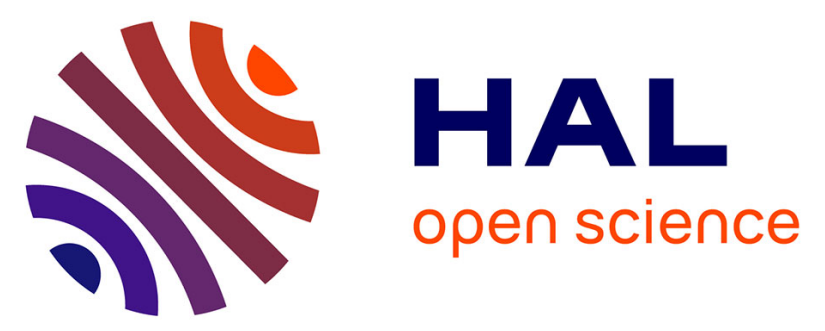

\title{
Evaluating the Diurnal Cycle of Upper-Tropospheric Ice Clouds in Climate Models Using SMILES Observations
} Jonathan H. Jiang, Hui Su, Chengxing Zhai, T. Janice Shen, Tongwen Wu, Jie Zhang, Jason N. S. Cole, Knut von Salzen, Leo J. Donner, Charles Seman, et al.

\section{To cite this version:}

Jonathan H. Jiang, Hui Su, Chengxing Zhai, T. Janice Shen, Tongwen Wu, et al.. Evaluating the Diurnal Cycle of Upper-Tropospheric Ice Clouds in Climate Models Using SMILES Observations. Journal of the Atmospheric Sciences, 2015, 72 (3), pp.1022-1044. 10.1175/JAS-D-14-0124.1 . hal01180034

\section{HAL Id: hal-01180034 \\ https://hal-polytechnique.archives-ouvertes.fr/hal-01180034}

Submitted on 12 Apr 2021

HAL is a multi-disciplinary open access archive for the deposit and dissemination of scientific research documents, whether they are published or not. The documents may come from teaching and research institutions in France or abroad, or from public or private research centers.
L'archive ouverte pluridisciplinaire HAL, est destinée au dépôt et à la diffusion de documents scientifiques de niveau recherche, publiés ou non, émanant des établissements d'enseignement et de recherche français ou étrangers, des laboratoires publics ou privés. 


\title{
Evaluating the Diurnal Cycle of Upper-Tropospheric Ice Clouds in Climate Models Using SMILES Observations
}

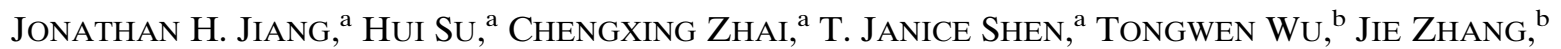 \\ Jason N. S. Cole, ${ }^{\mathrm{c}}$ KNut von SAlzen, ${ }^{\mathrm{c}}$ LeO J. Donner, ${ }^{\mathrm{d}}$ CHARles Seman, ${ }^{\mathrm{d}}$ ANTHONy Del Genio, \\ LARISSA S. NAZARENKO, ${ }^{\mathrm{e}}$ JEAN-LOUIS Dufresne, ${ }^{\mathrm{f}}$ MASAHIRO WATANABE, ${ }^{\mathrm{g}}$ CYRIL MORCRETTE, ${ }^{\mathrm{h}}$

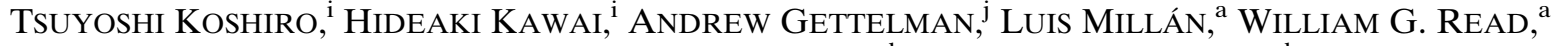 \\ NATHANIEl J. LiVESEY, ${ }^{a}$ YASKO KASAI, ${ }^{k}$ AND MASATO SHIOTANI ${ }^{1}$ \\ ${ }^{\text {a }}$ Jet Propulsion Laboratory, California Institute of Technology, Pasadena, California \\ ${ }^{\mathrm{b}}$ Beijing Climate Center, China Meteorological Administration, Beijing, China \\ ${ }^{\mathrm{c}}$ Canadian Centre for Climate Modeling and Analysis, Environment Canada, Victoria, British Columbia, Canada \\ ${ }^{\mathrm{d}}$ Geophysical Fluid Dynamics Laboratory, Princeton, New Jersey \\ ${ }^{\mathrm{e}}$ Goddard Institute for Space Studies, New York, New York \\ ${ }^{\mathrm{f}}$ Laboratoire de Météorologie Dynamique, Institute Pierre Simon Laplace, Paris, France \\ ${ }^{\mathrm{g}}$ Model for Interdisciplinary Research on Climate, Atmosphere and Ocean Research Institute, University of Tokyo, \\ Kashiwa, Japan \\ ${ }^{\mathrm{h}}$ Met Office Hadley Centre, Exeter, United Kingdom \\ ${ }^{\mathrm{i}}$ Meteorological Research Institute, Japan Meteorological Agency, Tsukuba, Japan \\ ${ }^{\mathrm{j}}$ National Center for Atmospheric Research, Boulder, Colorado \\ ${ }^{\mathrm{k}}$ National Institute of Information and Communications Technology, Tokyo, Japan \\ ${ }^{1}$ Research Institute for Sustainable Humanosphere, Kyoto University, Kyoto, Japan
}

(Manuscript received 30 April 2014, in final form 29 September 2014)

\begin{abstract}
Upper-tropospheric ice cloud measurements from the Superconducting Submillimeter Limb Emission Sounder (SMILES) on the International Space Station (ISS) are used to study the diurnal cycle of upper-tropospheric ice cloud in the tropics and midlatitudes $\left(40^{\circ} \mathrm{S}-40^{\circ} \mathrm{N}\right)$ and to quantitatively evaluate ice cloud diurnal variability simulated by 10 climate models. Over land, the SMILES-observed diurnal cycle has a maximum around 1800 local solar time (LST), while the model-simulated diurnal cycles have phases differing from the observed cycle by -4 to $12 \mathrm{~h}$. Over ocean, the observations show much smaller diurnal cycle amplitudes than over land with a peak at 1200 LST, while the modeled diurnal cycle phases are widely distributed throughout the 24-h period. Most models show smaller diurnal cycle amplitudes over ocean than over land, which is in agreement with the observations. However, there is a large spread of modeled diurnal cycle amplitudes ranging from $20 \%$ to more than $300 \%$ of the observed over both land and ocean. Empirical orthogonal function (EOF) analysis on the observed and modelsimulated variations of ice clouds finds that the first EOF modes over land from both observation and model simulations explain more than $70 \%$ of the ice cloud diurnal variations and they have similar spatial and temporal patterns. Over ocean, the first EOF from observation explains $26.4 \%$ of the variance, while the first EOF from most models explains more than $70 \%$. The modeled spatial and temporal patterns of the leading EOFs over ocean show large differences from observations, indicating that the physical mechanisms governing the diurnal cycle of oceanic ice clouds are more complicated and not well simulated by the current climate models.
\end{abstract}

\section{Introduction}

The most fundamental variabilities of Earth's weather and climate system are the diurnal and seasonal cycles,

Corresponding author address: Jonathan H. Jiang, Jet Propulsion Laboratory, 4800 Oak Grove Drive, Pasadena, CA 91011.

E-mail: jonathan.h.jiang@jpl.nasa.gov both of which are related to the surface temperature variations modulated by the position of the sun relative to Earth. The diurnal cycle, which is more poorly represented in climate models compared to the seasonal cycle (Yang and Slingo 2001), is driven by the higher surface temperature from solar heating during the day and the lower surface temperature from cooling to space during the night. In the morning, Earth's surface absorbs 
solar energy and heats a shallow layer of air directly above the ground by conduction and turbulent diffusion. Heat exchange between the warm air near the surface and the cooler air above can extend to the midtroposphere in convective air. The incoming solar radiation can exceed outgoing heat energy for several hours after noontime until a brief equilibrium is reached, before outgoing radiation exceeds the incoming at night. The exact time at which this equilibrium is reached is affected by a variety of factors, including the nature of the surface (e.g., ocean, land, or soil type), wind, clouds, water vapor, and surface moisture. The diurnal surface temperature variation drives the diurnal variation of atmospheric deep convection, which transports water vapor and cloud ice into the upper troposphere (UT). In turn, diurnal surface temperature variation could also be influenced by distribution of clouds, surface heat fluxes, transport of energy by the atmosphere, and the energy storage in the upper layers of the ocean or land. Thus, atmospheric diurnal cycles involve many processes and feedback mechanisms.

Studies of diurnal cycle of rainfall date back to as early as the 1920s (e.g., Ray 1928) and have been growing since then (e.g., Kraus 1963; Wallace 1975; McGarry and Reed 1978; Reed and Jaffe 1981; Albright et al. 1981, 1985; Houze and Betts 1981; Salby et al. 1991; Hendon and Woodberry 1993; Sui et al. 1998; Dai et al. 1999; Yang and Slingo 2001; Bechtold et al. 2004; Dai and Trenberth 2004; Tian et al. 2004; Lee et al. 2007; May et al. 2012). Most of these studies have focused on the diurnal variations in rainfall, for which the time lag in its response to the diurnal surface temperature variation is an important factor. For example, phase shifts of several hours between maximum rainfall and surface temperature have been observed both in the tropics (Yang and Slingo 2001; Bechtold et al. 2004), in the midlatitudes (Dai and Trenberth 2004; Lee et al. 2007), and in specific regions (e.g., Dai et al. 1999) focused on the United States, Australia, and midlatitude Canada and Russia.

The current understanding of diurnal rainfall variation and the physical mechanisms that drive them can be summarized as follows: Over continental land regions, it has been widely accepted that intensity of precipitation usually peaks in late afternoon from 1500 to 1800 local solar time (LST), associated with a direct time-lagged thermodynamic response of the surface layer to solar radiation (Kikuchi and Wang 2008; Feng et al. 2011); over ocean, convective precipitation is often characterized by an early morning peak with nocturnal maximum centered around 0300 LST (e.g., Nesbitt and Zipser 2003). The precise nature of the physical mechanism governing diurnal variability of rainfall over ocean, however, remains an open question (Yang and Slingo 2001; Tian et al. 2004; Kikuchi and Wang 2008). Near coastlines and along the land-sea boundaries of the maritime continents such as Indonesia, India, West Africa, and Brazil, the diurnal cycle is characterized by a precipitation peak of large amplitude that may occur anytime during the day, with the peak rainfall area potentially propagating perpendicular to the shoreline (e.g., Kikuchi and Wang 2008). The possible mechanisms under study for this regime include concavity (e.g., Nitis et al. 2005) of the shoreline and propagation of gravity waves (e.g., Pritchard and Somerville 2009; Sato et al. 2009).

For models to accurately simulate the global distribution of the diurnal cycles of clouds and precipitation, they must correctly incorporate all the relevant processes. It has been shown that the diurnal cycle plays an important role in the initialization of the Madden-Julian oscillation (MJO) (e.g., Johnson et al. 1999; Slingo et al. 2003). The diurnal cycle also impacts the convection entrainment rate and influences the frequency-intensity distribution of convective events, independent of how well the mean climate is simulated (e.g., Del Genio and $\mathrm{Wu}$ 2010; Stratton and Stirling 2012). Since the diurnal variation affects atmospheric circulation across a broad range of scales, from mesoscale convective systems (Yang and Slingo 2001) to intraseasonal oscillation (Tian et al. 2006), the accuracy of the diurnal cycle simulation is a key metric of climate model performance.

One of the well-documented deficiencies of many climate models is the too early onset of (maximum) daytime convection over land compared with observations. Del Genio and $\mathrm{Wu}$ (2010) pointed out that this is likely caused by insufficient sensitivity of their cumulus parameterizations to the state of the environment due to weak entrainment rates prescribed in the model. Bechtold et al. (2004) suggested that weakness in the convection schemes' triggering processes or parameterizations that affect the moisture and temperature profiles could also cause the early onset of deep convection. For example, an overestimation of surface temperature (or near-surface humidity) could enhance or cause the triggering of convection. Similarly, the air temperature above the boundary layer could affect convective inhibition, which determines the timing of convective initiation (Kuang and Bretherton 2006; Mapes 2000). The biases in model-simulated hydrologic variability on these short time scales suggest some lack of the physical mechanisms for convection in the models-largely deficiencies in convective parameterizations (Randall et al. 1991; Yang and Slingo 2001; Dai and Trenberth 2004). This is worrisome because the deficiencies in model physics could affect the simulated climate variabilities on longer time scales. Some cloud-resolving models 
(CRMs) show moderate improvements in capturing the diurnal variability (e.g. Liu and Moncrieff 1998); however, it is still computationally too expensive to use CRMs for climate projection studies.

To improve the models' ability to simulate diurnal cycles, we need global measurements of relevant physical quantities that can be simulated by models, and thus the model simulations can be evaluated. Besides the diurnal cycle of precipitation, a number of previous studies have investigated the diurnal cycles of cloud fraction, relative humidity, or top-of-atmosphere (TOA) radiative fluxes (e.g., Yang and Slingo 2001; May et al. 2012; Taylor 2012, 2014). However, there are relatively fewer studies on the diurnal cycle of UT ice clouds, which are closely related to deep convection (Soden 2000; Su et al. 2006; Tian et al. 2004). Recently, a number of studies have been conducted to evaluate clouds and moisture in the climate models participating in phase 5 of the Coupled Model Intercomparison Project (CMIP5) (e.g., Li et al. 2012; Jiang et al. 2012; Tian et al. 2013; Su et al. 2013; Klein et al. 2013; Dolinar et al. 2015; Stanfield et al. 2014). Jiang et al. (2012) showed the largest model errors are the simulations of ice cloud and water vapor in the UT. A comparison of modeled and observed diurnal variations of these quantities is a natural step to further check the model performance on shorter time scales and is useful for model improvements.

In this paper, we use the UT partial ice water path (pIWP) above the altitude of $200 \mathrm{hPa}(\sim 12 \mathrm{~km})$ measured by the Superconducting Submillimeter Limb Emission Sounder (SMILES) on the International Space Station (ISS) at different local times to study the diurnal variation of ice clouds in the UT for the tropical and midlatitude regions $\left(40^{\circ} \mathrm{S}-40^{\circ} \mathrm{N}\right)$. This dataset is then used to evaluate the performance of climate models in simulating the diurnal cycle of UT ice clouds. The SMILES data and model outputs of corresponding parameters are presented in sections 2 and 3, respectively. Section 4 presents modelobservation comparison and diagnosis. Section 5 summarizes the findings.

\section{SMILES observations}

Launched in September 2009, SMILES (Kikuchi et al. 2010) was a Japanese atmospheric limb sounding instrument on board the ISS. The SMILES instrument measured atmospheric thermal emission in three frequency bands (band A: 624.32-625.52 GHz, band B: $625.12-626.32 \mathrm{GHz}$, and band $\mathrm{C}: 649.12-650.32 \mathrm{GHz}$ ) on a time-sharing basis. The ISS is in a $51.6^{\circ}$ inclined orbit, which allowed SMILES to observe Earth with latitudinal coverage from about $60^{\circ} \mathrm{N}$ to $40^{\circ} \mathrm{S}$ on north-looking days

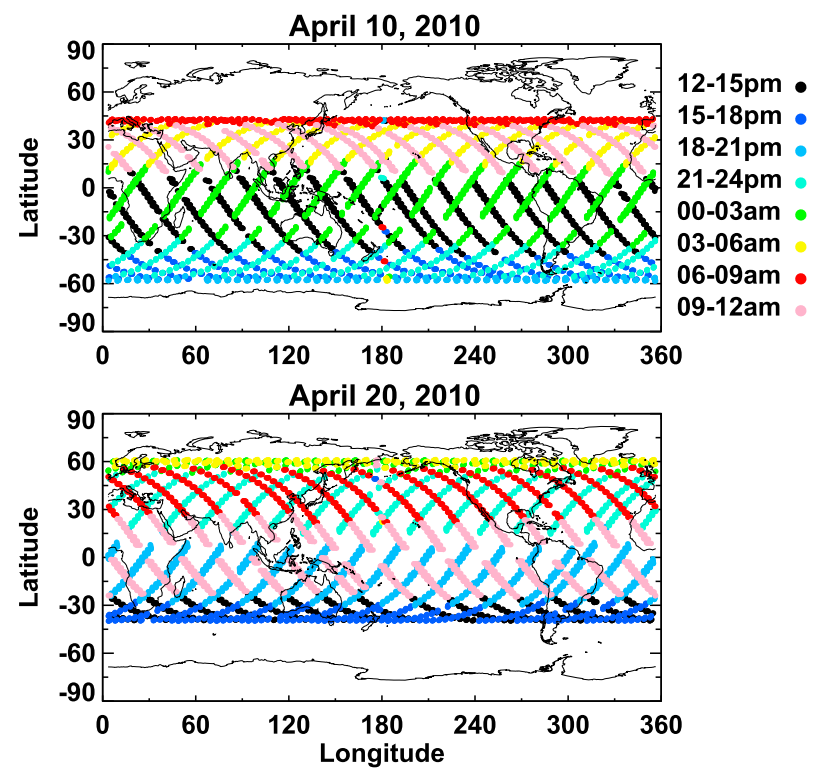

FIG. 1. Two examples of SMILES (band A) measurements at different LSTs on (top) a south-looking day and (bottom) a north-looking day.

and $40^{\circ} \mathrm{N}$ to $60^{\circ} \mathrm{S}$ on south-looking days (see example in Fig. 1) at different local times. These local times drifted about $20 \mathrm{~min}$ earlier each day, enabling coverage of entire diurnal cycle in a period of over a month (Manabe et al. 2008; Millan et al. 2013).

The SMILES pIWP product that we use in this study, described by Millan et al. (2013), is a result of the collaboration between the Jet Propulsion Laboratory (JPL) and Japanese partners. The pIWP $\left(\mathrm{g} \mathrm{m}^{-2}\right)$ is vertically integrated IWC above about $12-\mathrm{km}$ altitude (or about 200-hPa pressure level). It is derived from the simulated pIWP- $T_{\text {cir }}$ relationships similar to those used by the Aura Microwave Limb Sounder (MLS) experiment (Wu et al. 2006, 2008), where $T_{\text {cir }}$ is the retrieved cloud-induced radiance from SMILES's measurements (Millan et al. 2013). In short, $T_{\text {cir }}$ is the difference between the measured and expected clear-sky radiances; the latter are limb radiance simulations using GEOS-5 temperature and previously retrieved pressure, trace gases, and relative humidity. A $3 \sigma$ screening procedure similar to that described in Wu et al. (2008) and Livesey et al. (2013) for Aura MLS IWC data is performed to select the useful pIWP data. Since the frequencies of the three SMILES's bands (A, B, and C) are very close to each other, the differences of pIWP measurements between different bands are very small $(<0.1 \%)$ when averaged over the same period. The uncertainty for the pIWP is about $110 \%$ based on the analysis by Millan et al. (2013), which is interpreted as a scaling bias of a log-scale (base 10) factor of 2.04, mostly coming from 

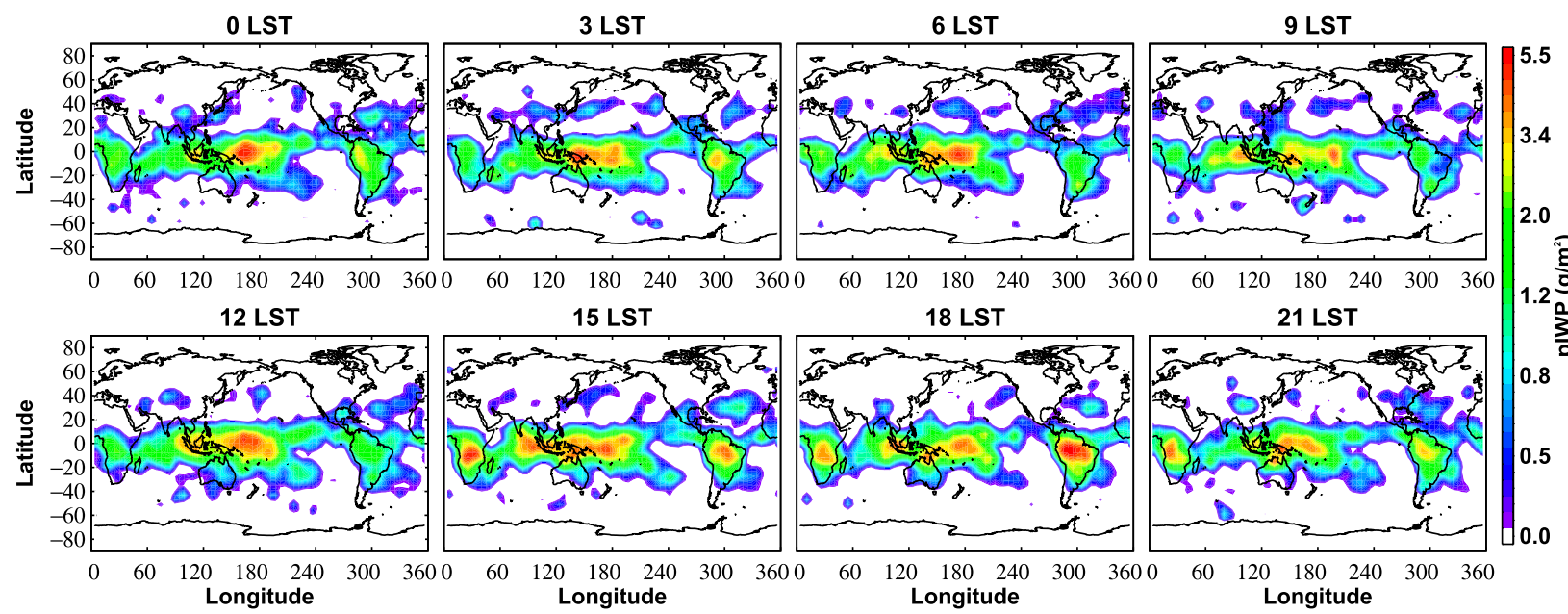

FIG. 2. The mean values of pIWP from SMILES binned at eight LST intervals. All SMILES measurements made from October 2009 to April 2010 are used in computing the average.

the potential scaling biases due to particle size assumptions used in the retrieval. Thus the uncertainty range of pIWP is about $50 \%$ of the pIWP at the lower end to $2 \times$ pIWP at the higher end, similar to the MLS IWC uncertainty (Jiang et al. 2012).

For comparison with climate models, the SMILES measurements are averaged over eight LST bins covering 3-h intervals centered at 0000, 0300, 0600, 0900 LST, etc. Figure 2 shows the spatial distributions of the observed pIWPs at eight LSTs $\left(\right.$ at $4^{\circ} \times 5^{\circ}$ latitude-longitude resolution), computed using all SMILES measurements by bands A, B, and C from 21 October 2009 to 21 April 2010, with standard bin averages weighted by the cosine of latitude. This period covers mainly the boreal winter season plus half of the late fall of 2009 and half of the early spring of 2010. As we can see from Fig. 2, highaltitude ice clouds above $200 \mathrm{hPa}$ are mostly distributed in the deep tropics within about $20^{\circ} \mathrm{S}-20^{\circ} \mathrm{N}$, with some occurrences extending to midlatitudes around $40^{\circ} \mathrm{S} / \mathrm{N}$. Because of the coarse sampling, the SMILES data are best suited for studying bulk features of diurnal cycles averaged over a large area and a period long enough to include sufficient samples for different LSTs, rather than local spatial or short temporal scales. A notable feature in Fig. 2 is that SMILES observed pIWPs over land regions (e.g., South America, Africa) peak around the late afternoon (1500-1800 LST), which will be discussed in more detail in the following two sections in comparison to model-simulated values.

\section{Climate models and MERRA reanalysis}

For this study, 10 climate models from nine modeling centers (Table 1) are analyzed. We obtain 3-hourly ice cloud mass mixing ratio (cli) to derive the IWC and
pIWP. All of the climate models are atmospheric global circulation models (GCMs) that participated in the CMIP5. The simulations conducted by these GCMs are forced with the observed sea surface temperatures (SST), sea ice fractions, $\mathrm{CO}_{2}$ concentrations, and other external forcings as defined in the Atmospheric Model Intercomparison Project (AMIP) framework (Taylor et al. 2012). The modeled pIWP are computed by integrating IWCs from the 200-hPa level upward. For models that do not have the exact 200-hPa level, a linear interpolation based on log pressure is applied to calculate the $200-\mathrm{hPa}$ IWC before the pIWP integration. For the 3-hourly output, CCCma, GISS, and MIROC models provide special simulations for the October 2009-April 2010 period as in the SMILES observations, while for other models the 3-hourly output of the OctoberApril period are produced from their existing AMIP runs of the most recent year when model data are available (Table 1). Our analysis has found that the choice of different years and small changes in the lower bound of the pressure level used in the pIWP integration do not affect the diurnal cycle phase and amplitude significantly (see appendix).

In the following, we summarize the main features of each model.

\section{a. $B C C$}

The Beijing Climate Center Climate System Model, version 1.1 (BCC-CSM1.1), is described by $\mathrm{Wu}$ et al. (2010, 2013). The atmospheric component of the model used for this study has a horizontal resolution of approximately $2.8^{\circ} \times 2.8^{\circ}(\mathrm{T} 42)$ and 26 vertical levels. Its convection scheme is described by Wu (2012). Deep convection is launched at the level of maximum moist static energy above the top of the boundary layer and 
TABLE 1. Climate centers and models that participated in this study.

\begin{tabular}{|c|c|c|c|c|c|}
\hline & & & \multicolumn{2}{|c|}{ Available data } & \multirow[b]{2}{*}{ References } \\
\hline \multicolumn{2}{|l|}{ Climate modeling center } & Model & Period & 3 hourly & \\
\hline Beijing Climate Center, China & $\mathrm{BCC}$ & $\begin{array}{l}\text { BCC-CSM1.1, } \\
\text { BCC-CSM1.1m }\end{array}$ & October 2004-April 2005 & Average & $\begin{array}{l}\text { Wu et al. (2010); } \\
\text { Wu et al. (2013) }\end{array}$ \\
\hline $\begin{array}{l}\text { Canadian Centre for Climate } \\
\text { Modeling and Analysis, } \\
\text { Canada }\end{array}$ & CCCma & CanAM4 & October 2009-April 2010 & Instantaneous & $\begin{array}{l}\text { von Salzen et al. (2013); } \\
\text { Scinocca and McFarlane } \\
\text { (2013); Zhang and } \\
\text { McFarlane (1995) }\end{array}$ \\
\hline $\begin{array}{l}\text { Geophysical Fluid Dynamics } \\
\text { Laboratory, United States }\end{array}$ & GFDL & AM3 & October 2006-April 2007 & Average & $\begin{array}{l}\text { Donner et al. (2011); } \\
\text { Benedict et al. (2013) }\end{array}$ \\
\hline $\begin{array}{l}\text { NASA Goddard Institute for } \\
\text { Space Studies, United States }\end{array}$ & GISS & ModelE2 & October 2009-April 2010 & Average & Schmidt et al. (2014) \\
\hline $\begin{array}{l}\text { Institut Pierre Simon Laplace, } \\
\text { France }\end{array}$ & IPSL & CM5-LRA & $\begin{array}{l}\text { October } 2008 \\
\text { January } 2009 \\
\text { April } 2009\end{array}$ & Instantaneous & $\begin{array}{l}\text { Dufresne et al. (2013); } \\
\quad \text { Hourdin et al. (2013) }\end{array}$ \\
\hline $\begin{array}{l}\text { Model for Interdisciplinary } \\
\text { Research on Climate, Japan }\end{array}$ & MIROC & MIROC5 & October 2009-April 2010 & Instantaneous & $\begin{array}{l}\text { Watanabe et al. (2010); } \\
\text { Watanabe et al. (2009); } \\
\text { Wilson and Ballard } \\
\text { (1999); Chikira and } \\
\text { Sugiyama (2010) }\end{array}$ \\
\hline $\begin{array}{l}\text { Met Office, Hadley Center, } \\
\text { United Kingdom }\end{array}$ & MOHC & HadGem2-a & October 2009-April 2010 & Instantaneous & $\begin{array}{l}\text { Derbyshire et al. (2011); } \\
\text { Collins et al. (2008); } \\
\text { Wilson and Ballard } \\
\text { (1999); Gregory (1999) }\end{array}$ \\
\hline $\begin{array}{l}\text { Meteorological Research } \\
\text { Institute, Japan }\end{array}$ & MRI & CGCM3 & $\begin{array}{l}\text { January-April 2008, } \\
\text { October-December } \\
2008\end{array}$ & Instantaneous & $\begin{array}{l}\text { Yukimoto et al. (2011); } \\
\text { Yukimoto et al. (2012) }\end{array}$ \\
\hline $\begin{array}{l}\text { National Center for } \\
\text { Atmospheric } \\
\text { Research, United States }\end{array}$ & NCAR & CAM5 & October 2007-April 2008 & Average & $\begin{array}{l}\text { Gettelman et al. (2010); } \\
\text { Park and Bretherton } \\
\text { (2009); Zhang and } \\
\text { McFarlane (1995) }\end{array}$ \\
\hline
\end{tabular}

triggered if the convective available potential energy (CAPE) is positive and the relative humidity of the air at the lifting level of the convective cloud is greater than $75 \%$. The entrainment (detrainment) amount for the updraft cloud parcel is separately determined according to the increase (decrease) of updraft parcel mass with altitude, while the mass change for the adiabatic ascent cloud parcel with altitude is derived from a total energy conservation equation of the whole adiabatic system that involves the updraft cloud parcel and the environment. The mass flux at the base of convective cloud is determined by a closure scheme (Zhang 2002), in which the increase (decrease) of CAPE in response to changes in the thermodynamic states of the free troposphere resulting from convection approximately balances the decrease (increase) from large-scale processes (Wu 2012). The BCC-CSM1.1m is essentially the same model as BCC-CSM1.1, except that the horizontal resolution of its atmospheric component is approximately $1.1^{\circ} \times 1.1^{\circ}(\mathrm{T} 106)$. In this study, we will use the lower-resolution BCC-CSM1.1 in general, unless otherwise specified; therefore, in most of the cases, we have nine models.

\section{b. CCCma}

The CCCma fourth Canadian Atmospheric Model (CanAM4) is used for this study. Details about the CanAM4 physical parameterizations are given in von Salzen et al. (2013). Deep convection in CanAM4 uses the parameterization of Zhang and McFarlane (1995) along with a prognostic closure based on CAPE (Scinocca and McFarlane 2013). The model has horizontal resolution of T63 and 35 vertical levels.

\section{c. GFDL}

The GFDL AM3, as documented in Donner et al. (2011), is the atmospheric component of the GFDL coupled model CM3. Both AM3 and CM3 participated in CMIP5. AM3 has a deep cumulus parameterization that uses a CAPE-based closure. The version that produced 3-hourly data for this study is identical to the CMIP5 version of AM3 except for details of the trigger and closure mechanisms for the deep cumulus parameterization. Specifically, this model version, described in Benedict et al. (2013), requires sufficient time-integrated low-level lift to move a near-surface parcel to its level of 
free convection before deep convection can occur. Its closure requires that the deep cumulus heating balance changes in CAPE are not produced by the changes in the boundary layer. The model has $2^{\circ} \times 2.5^{\circ}$ horizontal resolution and 48 vertical layers.

\section{d. GISS}

The GISS ModelE2 is used for this study. In the CMIP5 archive, the ModelE2 climate model with the Russell ocean model (Russell et al. 1995) is referred to as GISS E2-R. For this study, the 3-hourly IWC outputs are produced by GISS E2-R's noninteractive version (NINT) atmospheric model. The model has $2^{\circ} \times 2.5^{\circ}$ horizontal resolution and 40 vertical layers. The basic physics of the model is described by Schmidt et al. (2014).

\section{e. IPSL}

The IPSL CM5 model is described in Dufresne et al. (2013) and Hourdin et al. (2013). The IPSL-CM5A-LR version of the model has been used to perform most of the numerical experiments proposed by CMIP5. The 3-hourly output from the IPSL-CM5A-LR AMIP experiment is downloaded through the Program for Climate Model Diagnosis and Intercomparison (PCMDI) Earth System Grid (ESG) database at http://pcmdi9.1lnl. gov/. The model has a horizontal resolution of $1.875^{\circ} \times$ $3.75^{\circ}$ and 40 vertical levels.

\section{f. MIROC}

The MIROC5 model is described by Watanabe et al. (2010). Its atmospheric model includes a large-scale condensation scheme with prognostic cloud (Watanabe et al. 2009), cloud microphysics for prognostic cloud liquid and ice (Wilson and Ballard 1999), an aerosol module with prognostic cloud condensation nuclei $(\mathrm{CCN})$ (Takemura et al. 2005), and a cumulus convection scheme with statedependent entrainment (Chikira and Sugiyama 2010). The model has a horizontal resolution of $1.4^{\circ} \times 1.4^{\circ}$ and 40 vertical levels.

\section{g. $\mathrm{MOHC}$}

The HadGEM2-A is an atmospheric model that participated in CMIP5. The model is described in Collins et al. (2008). Its prognostic cloud IWC is calculated following Wilson and Ballard (1999). The large-scale ice cloud fraction is diagnostically calculated from the IWC. Liquid cloud water content and cloud cover are parameterized following Smith (1990). The convection scheme is based on Gregory and Rowntree (1990) but without the depth criterion for shallow convection. The scheme also includes an "adaptive detrainment" parameterization (Derbyshire et al. 2011). In addition to the large-scale cloudiness, the model represents the radiative impact of convective clouds (Gregory 1999). When the convection scheme is active, a convective cloud cover (diagnosed from the convective precipitation rate) and cloud water content are added to the clouds seen by radiation. These convective clouds are stationary and decay after convective activity with a half-life of $2 \mathrm{~h}$. The model has a horizontal resolution of $1.875^{\circ} \times 1.25^{\circ}$ and 38 vertical levels.

\section{h. $M R I$}

The model used for this study is the same as that used for the AMIP-type experiment of CMIP5, which is the atmospheric part of MRI-CGCM3 (Yukimoto et al. 2011, 2012). The model has a horizontal resolution of approximately $1.1^{\circ} \times 1.1^{\circ}$ and 48 vertical levels. A mass flux-type Yoshimura cumulus scheme (Yoshimura et al. 2015) is used as a convection scheme for the atmospheric model. The scheme considers an ensemble of convective updrafts, and the closure assumption is based on CAPE. The cloud scheme is a two-moment bulk scheme (the MRI-TMBC scheme), in which the prognostic variables are the cloud liquid water and cloud ice mixing ratios, cloud droplet and ice crystal concentrations, and cloud fraction. Convective clouds are not considered explicitly and the detrained cloud liquid water and ice from convections are handed over to the cloud scheme as stratiform anvil clouds.

\section{i. NCAR}

The data produced for this study are from the NCAR CAM5 model, which is the atmospheric component of the NCAR CESM1. The model has $0.9^{\circ} \times 1.25^{\circ}$ horizontal resolution with 30 vertical levels. The Park and Bretherton (2009) scheme is employed for shallow convection, and Zhang and McFarlane (1995) scheme is used for deep convection, in which convective clouds detrain ice or liquid water (phase determined by temperature) into the large-scale cloud scheme. Also, a parameterization of homogeneous ice nucleation and heterogeneous immersion nucleation in cirrus clouds (Liu and Penner 2005) is implemented in the microphysics scheme. The large-scale condensation scheme permits ice supersaturation as described by Gettelman et al. (2010).

In addition to climate model simulations, we also use the Modern-Era Retrospective Analysis for Research and Applications (MERRA) reanalysis 3-hourly water vapor data, which are generated using version 5 of the Goddard Earth Observing System (GEOS) Data Assimilation System (DAS). The MERRA focuses on historical analyses of the hydrological cycle on a broad range of weather and climate time scales. The horizontal resolution of MERRA data is $1.25^{\circ}$ longitude $\times 1.25^{\circ}$ latitude, with 42 vertical pressure levels.

For the purpose of model-observation comparisons discussed hereafter, all pIWPs from SMILES, climate 
Diurnal Variation Over Land Diurnal Variation Over Ocean
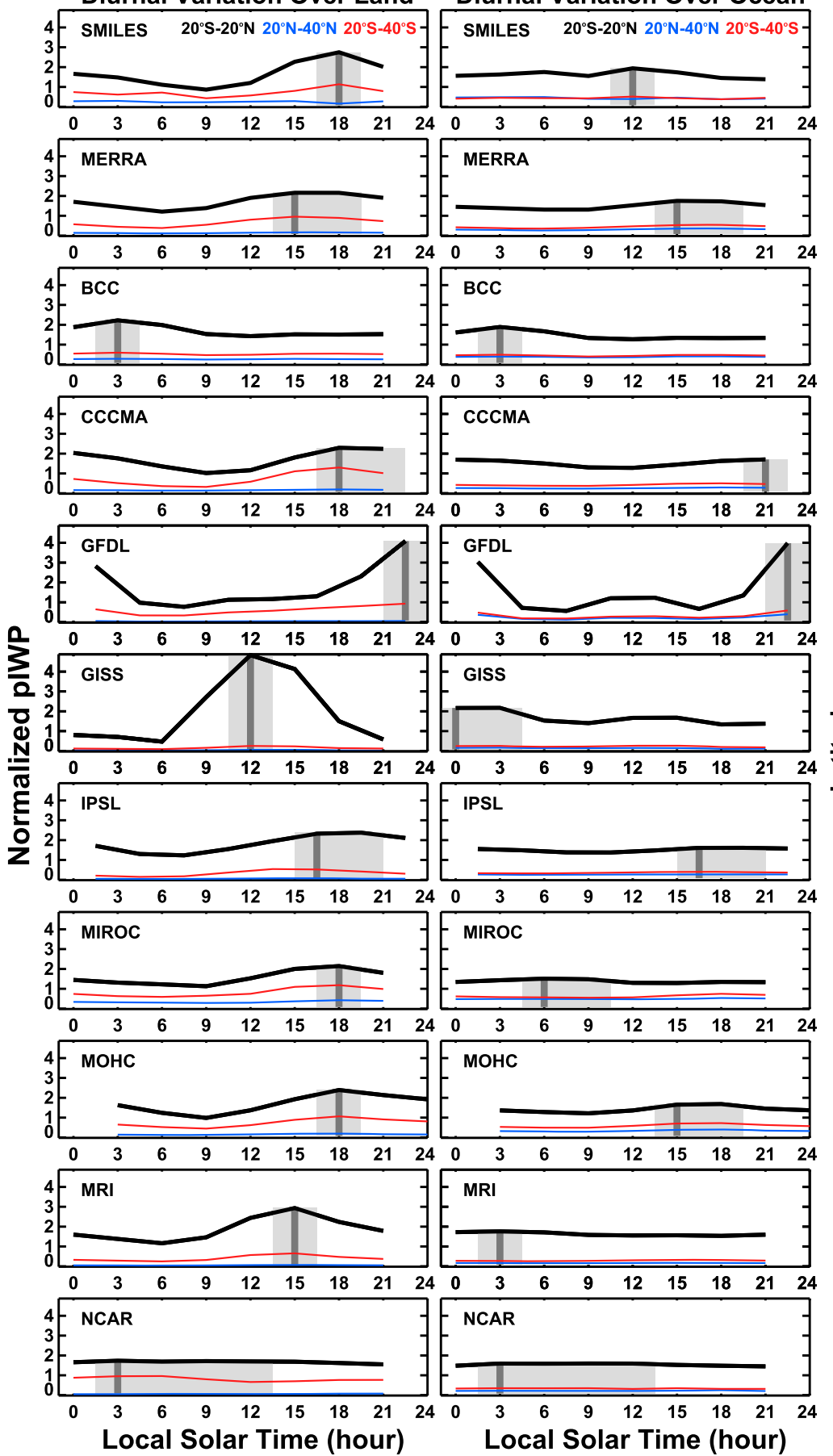

Mean State ("Daily Mean") SMıLES
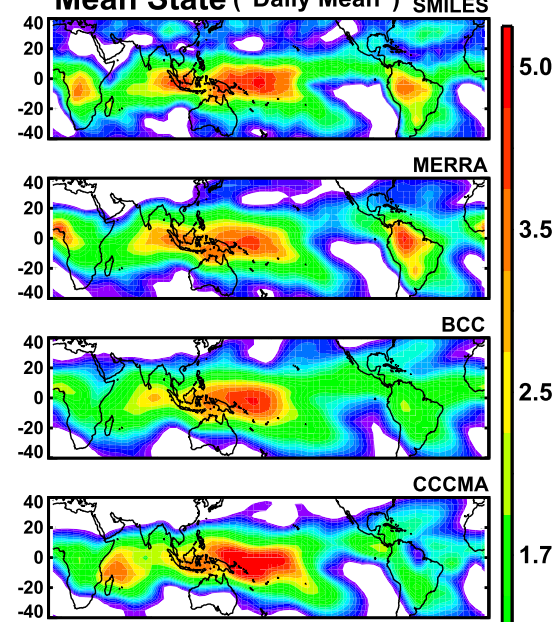

3.5

2.5

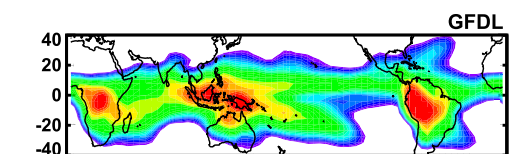

1.2
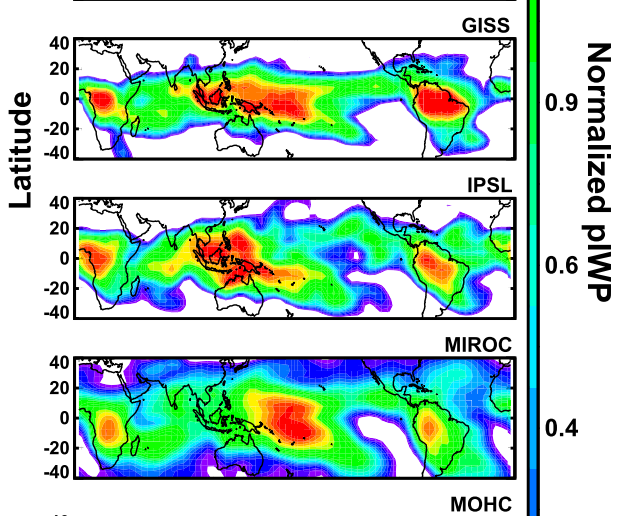

0.4
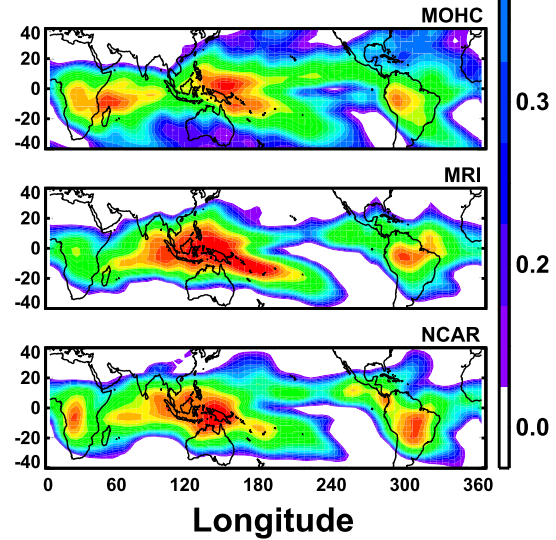

FIG. 3. Diurnal variability of normalized pIWP over (left) land and (middle) ocean for tropics (black curve), northern midlatitudes (blue curve), and southern midlatitudes (red curve). The gray bar and shaded area represent the maximum pIWP and its duration, respectively. Some of the model curves (GFDL, IPSL, MOHC) cover LST ranges different from the others owing to different model output time (instantaneous or center of the 3-hourly average). (right) Normalized mean-state ("daily mean") pIWP maps; all values are normalized by the $40^{\circ} \mathrm{S}-40^{\circ} \mathrm{N}-\mathrm{mean}$ pIWP.

models, and MERAA reanalysis are regridded onto the same $4^{\circ} \times 5^{\circ}$ latitude-longitude grids. The diurnal variations are constructed by sorting data into the same 3-hourly LST bins.

\section{Model-observation comparisons}

Figure 3 compares the October-April-averaged pIWP from SMILES observations, MERRA reanalysis, and 
nine climate models. All data are normalized by the mean value of pIWP averaged over $40^{\circ} \mathrm{S}-40^{\circ} \mathrm{N}$, which will be discussed later in section $4 \mathrm{c}$. The first and second columns are the normalized pIWP as a function of LST over land and ocean, respectively, for tropical $\left(20^{\circ} \mathrm{S}-\right.$ $\left.20^{\circ} \mathrm{N}\right)$, northern midlatitude $\left(20^{\circ}-40^{\circ} \mathrm{N}\right)$, and southern midlatitude $\left(20^{\circ}-40^{\circ} \mathrm{S}\right)$ regions. The vertical gray bars in these figures indicate the LSTs when the tropical mean pIWP reaches its peak value; the lighter gray shades mark the time span that tropical pIWP continues at its peak values. The MERRA reanalysis and a few models, including CCCma, IPSL, and NCAR, have pIWP values remain nearly unchanged $(<2 \%$ difference) after reaching a maximum for more than one LST bin. In this case, the gray shade spans from $1.5 \mathrm{~h}$ before the starting pIWP peak LST to $1.5 \mathrm{~h}$ after the peak pIWP occurs. The reason for such a larger interval when the peak values are close is probably due to the coarsely sampled LST interval of model outputs. The actual peak probably resides somewhere within the gray shade.

The third column in Fig. 3 shows the normalized mean pIWP maps averaged for all LSTs over the OctoberApril period. As will be discussed in section 3c, the absolute values of the mean-state pIWP have a large spread among the models. Here the normalized maps show that the spatial patterns of average pIWP are generally similar among the models and also between the models and observations, indicating that models simulate the spatial distribution of deep convection fairly well compared with the simulated absolute ice cloud amount (Jiang et al. 2012). However, notable differences exist: BCC and CCCma models have much smaller normalized pIWPs over land than over ocean, while GFDL model has a relatively larger ice cloud amount over land; the UT ice clouds in the GISS model are confined over the deep tropics, with little occurrence over the midlatitudes; in the MIROC model, high concentration of ice clouds is somewhat shifted eastward into the central Pacific, rather than over the western Pacific as in other models and the SMILES observation. Since high clouds are typically observed over deep convective regions, the spatial pattern differences of the model ice cloud distribution could be associated with different convective schemes and large-scale circulations (Su et al. 2011, 2013). Since large diurnal variations are generally observed over the deep convective regions (e.g., Hendon and Woodberry 1993; Soden 2000; Yang and Slingo 2001), the difference in modeled mean-state ice cloud distribution patterns could also cause their diurnal cycle differences.

\section{a. Diurnal cycle over land}

Over land (first column in Fig. 3), SMILES observations show a strong pIWP peak in the late afternoon to early evening around 1800 LST, which is consistent with the traditional view that the convective clouds over land are strongly influenced by thermodynamic response to the diurnal cycle of the surface temperature. When the solar heating warms the land surface temperature during the daytime, the lower-tropospheric temperature-and therefore the air instability-increases, leading to the development of deep convective cloud systems responsible for the UT ice cloud formation. SMILES observations show that such ice clouds, as indicated by pIWP, start to increase after noontime and the time lag for reaching the maximum is about $6 \mathrm{~h}$ after the noontime when the sun appears the highest in the sky. After sunset, the nighttime radiative cooling decreases surface temperature, enhances the atmospheric stability, and thus suppresses deep convection. This is reflected in the SMILES observation as the pIWP amount decreases at night and continues to reach the minimum around 0900 LST when the sun is low in the sky. For midlatitude regions, the pIWPs and their diurnal variations are much smaller, corresponding to less convection compared to the deep tropics. However, there is a substantial Southern and Northern Hemispheric difference due to different seasons. It is known that deep convection, which transports moisture and ice into the UT, is generally stronger in the summer hemisphere (e.g., Jiang et al. 2010), unlike in the tropics where it happens all year round. During the October-April period, the southern midlatitudes were undergoing mostly summertime while the northern midlatitudes were mainly experiencing wintertime. Therefore pIWP values in the southern midlatitudes (red curve) are larger than those in the northern midlatitudes (blue curve) and exhibit a diurnal variation similar to that in the tropics. The total amounts of and the diurnal variations in pIWP in the northern midlatitudes are negligibly small.

The diurnal cycle of pIWP over land is approximately captured by the MERRA reanalysis, except that its maximum occurs about $3 \mathrm{~h}$ earlier than the SMILES observation. It also appears that the MERRA's pIWP peak lasts longer from 1500 to 1800 LST, which is likely because of the coarse 3-hourly temporal resolution of the MERRA output; the real peak is probably between 1500 and 1800 LST. MERRA produces similar pIWP differences between the southern and northern midlatitudes to those observed by SMILES.

For climate models, the diversity is large. Three models-CCCma, MIROC, and MOHC-correctly simulate the local times when the maximum and the minimum of observed pIWP are reached. These three models also simulate the differences between the southern and northern midlatitudes similarly to the SMILES observation. For the CCCma model, the peak pIWP may 
occur slightly after 1800 LST or between 1800 and 2100 LST. In the IPSL model the maximum pIWP is reached near 1800 LST but the minimum is reached about $2 \mathrm{~h}$ earlier than observed. The MRI model has a peak pIWP at 1500 LST and a minimum pIWP at 0600 LST, both $3 \mathrm{~h}$ earlier than the observations. The NCAR model has the least diurnal variability of pIWP with a very weak maximum extending from early morning to noon (between 0300 and 1200 LST). The GISS model has a very strong maximum pIWP at noontime (1200 LST) and a broad minimum pIWP at night between 2100 and 0600 LST. The two models that have nocturnal pIWP peak are the BCC model, with a peak pIWP at 0300 LST, and the GFDL model, which simulates a very strong pIWP maximum close to midnight. All models, however, capture north-south seasonal differences in pIWP - more or less the same way as in the observations.

\section{b. Diurnal cycle over oceans}

Over ocean (second column in Fig. 3), the SMILES observations show a much smaller diurnal variation than that over land owing to relatively weaker oceanic convection than land convection (Tian et al. 2004; Gary and Jacobson 1977). The diurnal cycle over ocean also reaches its maximum and minimum at different LSTs compared to those over land. In the tropical region, the pIWP reaches the maximum at noontime (1200 LST) and a secondary weaker peak at 0600 LST. The results are consistent with a similar bimodal distribution found in the longwave cloud forcing diurnal cycle by Taylor (2012), and are also consistent with the trimodal structure of tropical convective clouds and corresponding diurnal cycles: early morning shallow convection, afternoon scattered convection, and nocturnal organized convection (Johnson et al. 1999).

In both the southern and northern midlatitudes, the pIWPs are much smaller, with little diurnal variations.

The MERRA reanalysis and many climate modelsincluding BCC, CCCma, GFDL, IPSL, MOHC, and NCAR - simulate the oceanic pIWP maxima and minima occurring at the same LSTs as those over land. However, unlike over land, most models have much smaller pIWP diurnal variation amplitudes and the differences between the northern and southern midlatitudes are much less, which agree with the observations. The exception is the GFDL model, which had similar diurnal variation amplitude over ocean compared to that over land. GFDL oceanic pIWP also show a secondary maximum at 1200 LST.

The models that show significant differences between land and ocean are GISS, MIROC, and MRI. For the GISS model, the LST for the maximum of tropical mean pIWP changes from noontime over land to midnight over ocean. For the MIROC model, the maximum
pIWP occurs at early morning (0600 LST) over ocean, compared to late afternoon (1800 LST) over land, but the oceanic pIWP maximum over the southern midlatitude is at the same LST as over land. For the MRI model, the amplitude of the oceanic pIWP diurnal cycle at all latitudes becomes very weak $(\sim 3 \%$ above the mean) and also shifted from 1500 LST over land to 0000 LST (midnight) over ocean.

The physical mechanisms behind the diurnal cycles of deep convective clouds over ocean are more complicated than over land. It has been shown that SST has only a weak diurnal cycle of less than about $1 \mathrm{~K}$ (Chen and Houze 1997) that is mainly noticeable in low wind regions such as the intertropical convergence zone (ITCZ) and South Pacific convergence zone (SPCZ) and usually peaks in the early afternoon (e.g., Chen and Houze 1997; Stuart-Menteth et al. 2003). Such SST warming provides a favorable condition for the formation of deep convective ice clouds (e.g., Su et al. 2006). However, convective clouds may not develop immediately after SST reaches maximum. Chen and Houze (1997) studied the life cycle of large oceanic convective cloud systems and found these systems can undergo a life cycle of more than half a day and reach maximum during night hours before dawn and subsequently decay after sunrise. Randall et al. (1991), on the other hand, studied radiation-convection interaction and suggested that the IR cooling at cloud tops can result in destabilization of the UT, leading to convection development with a maximum occurring in the early morning. Also, the diurnal cycle of oceanic convection near the coastal regions may be influenced by the diurnal cycle of deep convection over the nearby land (Yang and Slingo 2001). Presumably, the above mechanisms act together to modulate the diurnal cycle of oceanic convective clouds, and sometimes one physical mechanism may dominate the others, which poses a great challenge for climate models and even the reanalysis model to capture.

\section{c. Quantitative model performance evaluation 1: Mean state, diurnal cycle phase lag, and diurnal variation amplitude}

We now quantify the model-observation differences by comparing the October-April, $40^{\circ} \mathrm{S}-40^{\circ} \mathrm{N}$-averaged pIWP mean states, diurnal cycle phase lags, and diurnal variation amplitudes, as shown in Fig. 4.

The top panels of Fig. 4 show the normalized mean state, where the light gray horizontal band shows the uncertainty range for the SMILES pIWP data. Over land (Fig. 4, top-left panel), five models (BCCm, CCCma, IPSL, MIROC, and NCAR) have mean pIWPs that fall within the uncertainty range, indicating their agreement with the observation. Note that the two BCC models only 

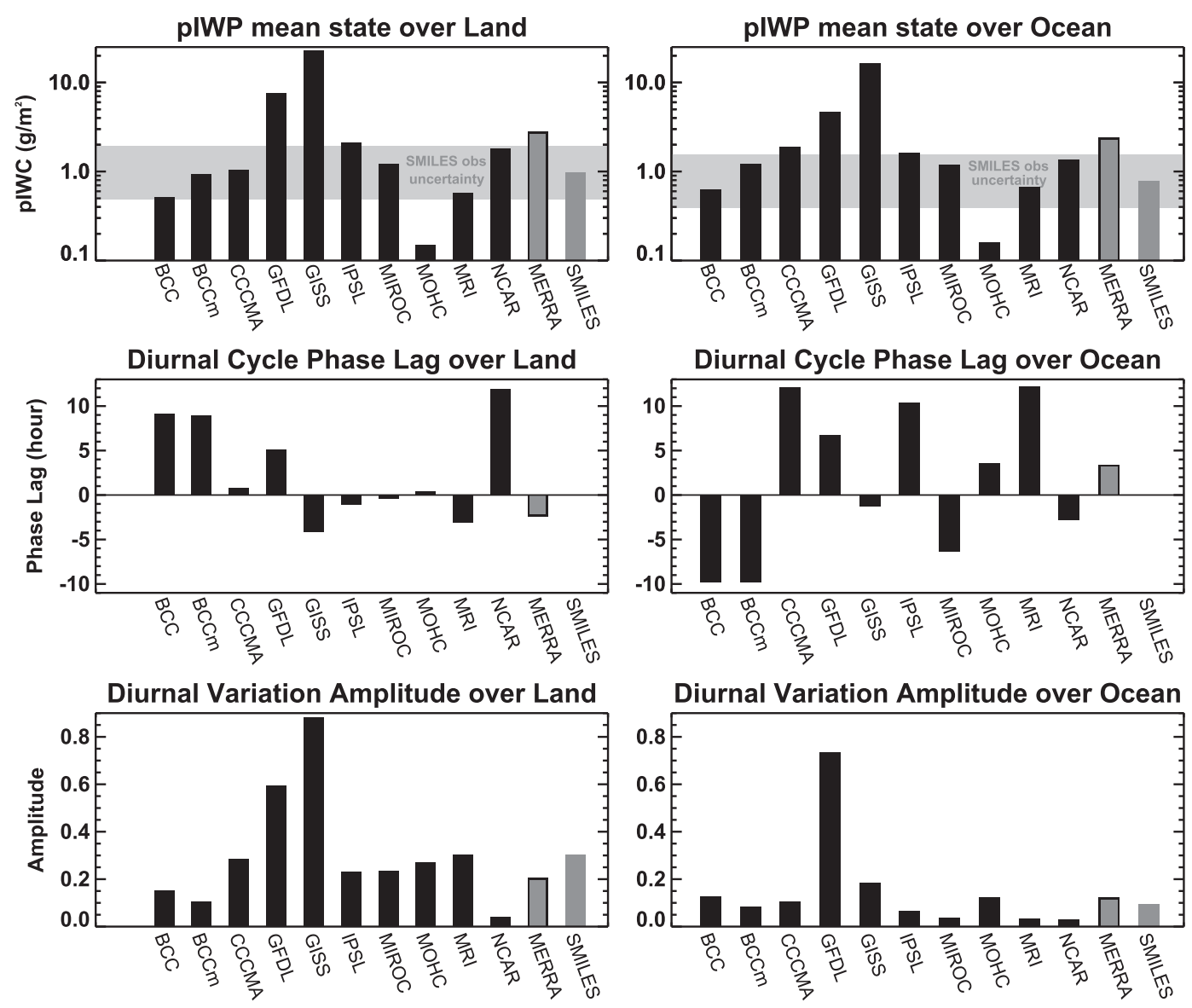

FIG. 4. Model-observation comparisons of (top) mean state, (middle) phase lag, and (bottom) amplitude over (left) land and (right) ocean. Note that the two BCC models have the same physics package; the only difference is that the BCCm ("m" is short for CSM1.1m) model has higher horizontal resolution than the standard BCC.

differ in resolution; BCCm (" $\mathrm{m}$ " is short for CSM1.1m) model has 2.5-times-higher spatial resolution than the standard BCC model, which suggests that improving model resolution helps improve the simulated meanstate ice cloud amount. Three models-BCC, MOHC, and MRI-simulate too small pIWP amounts while other two GFDL and GISS simulate too large pIWPs compared with the SMILES observation.

For the mean state over ocean (Fig. 4, top-right panel), the models that agree well with the observations are BCC, BCCm, IPSL, MIROC, and NCAR. MOHC and MRI models had too small pIWPs while CCCma, GFDL, and GISS had too large pIWPs. We note there are large spreads of modeled mean-state pIWPs over both land and ocean (a factor of about 50), which is consistent to the findings by Jiang et al. (2012). We quantify the model performance in simulating the mean-state pIWP using combined mean-state values, spatial correlation, and spatial variances scores as in Jiang et al. (2012). The results are listed in Table 2 . We can see that for ice cloud only [without considering water vapor as in Jiang et al. (2012)], the BCC model, especially the higher-resolution BCCm, scores the highest in simulating the mean-state pIWP over both the land (0.86) and ocean (0.90). Over land, CCCma and MIROC are tied with BCC-CSM1.1m scoring 0.86 , followed by IPSL and NCAR, scoring 0.76 and 0.73 , respectively. Over ocean, the top-scored models after the two BCC models are MIROC (0.79), IPSL (0.76), and MRI (0.71), followed closely by NCAR, which scores 0.70 .

However, a model that simulates good mean states does not guarantee its diurnal cycle to be also reasonably simulated. The models' diurnal cycle phase lag and amplitude are useful metrics to measure how well the daytime solar heating and nighttime radiative cooling near the surface and their influence on deep convection strength and high-cloud amount are captured in the models. The phase lags, shown in the middle panels of Fig. 4 (and also listed in Table 2), are computed by cross correlating the model's diurnal variation $M(t)$ to the SMILES-observed diurnal variation $S(t)$ with fractional lags estimated by the spectral interpolation method 
TABLE 2. Model-observation comparisons of mean state, phase lag, amplitude, and spatial and temporal pattern similarities over land and ocean. Mean-state score is computed using the scoring system described by Jiang et al. (2012), which quantifies a climate model performance in simulating cloud ice based on its spatial mean, spatial correlation, and spatial variances. Phase lag is computed by cross correlating model-simulated diurnal cycle to the SMILES-observed diurnal cycle using the spectral interpolation method described in section 4c. Amplitude is the normalized standard deviation of pIWPs sampled at eight different LSTs. Spatial pattern similarity is computed by the inner product of the patterns of first EOF mode of pIWP diurnal variability [i.e., Eq. (7)]. Temporal pattern similarity is computed as the maximum value of cross correlation between the model and observation defined by Eq. (2).

\begin{tabular}{|c|c|c|c|c|c|c|c|c|c|c|}
\hline \multirow[b]{3}{*}{ Model } & \multirow{2}{*}{\multicolumn{2}{|c|}{ Mean-state score }} & \multirow{2}{*}{\multicolumn{2}{|c|}{$\begin{array}{l}\text { Diurnal cycle } \\
\text { phase lag (h) }\end{array}$}} & \multirow{2}{*}{\multicolumn{2}{|c|}{$\begin{array}{l}\text { Diurnal cycle } \\
\text { amplitude }\end{array}$}} & \multicolumn{4}{|c|}{ Pattern similarity } \\
\hline & & & & & & & \multicolumn{2}{|c|}{ Spatial } & \multicolumn{2}{|c|}{ Temporal } \\
\hline & Land & Ocean & Land & Ocean & Land & Ocean & Land & Ocean & Land & Ocean \\
\hline SMILES & 1.00 & 1.00 & 0.0 & 0.0 & 0.30 & 0.10 & 1.00 & 1.00 & 1.00 & 1.00 \\
\hline MERRA & 0.56 & 0.62 & -2.5 & 3.4 & 0.21 & 0.12 & 0.77 & 0.39 & 0.90 & 0.43 \\
\hline BCC-CSM1.1 & 0.73 & 0.84 & 9.0 & -9.9 & 0.15 & 0.13 & 0.80 & 0.32 & 0.93 & 0.54 \\
\hline BCC-CSM1.1m & 0.90 & 0.85 & 9.2 & -9.8 & 0.11 & 0.09 & 0.70 & 0.30 & 0.87 & 0.63 \\
\hline CCCma & 0.90 & 0.65 & 0.9 & 12.1 & 0.28 & 0.10 & 0.78 & 0.32 & 0.88 & 0.58 \\
\hline GFDL & 0.27 & 0.36 & 5.1 & 6.7 & 0.59 & 0.73 & 0.76 & 0.31 & 0.89 & 0.69 \\
\hline GISS & 0.25 & 0.27 & -4.2 & -1.3 & 0.88 & 0.19 & 0.83 & 0.12 & 0.94 & 0.49 \\
\hline IPSL & 0.62 & 0.60 & -1.1 & 10.4 & 0.23 & 0.07 & 0.81 & 0.24 & 0.86 & 0.42 \\
\hline MIROC & 0.86 & 0.79 & -0.5 & -6.4 & 0.23 & 0.04 & 0.90 & 0.05 & 0.95 & 0.52 \\
\hline $\mathrm{MOHC}$ & 0.36 & 0.37 & 0.4 & 3.6 & 0.27 & 0.12 & 0.91 & 0.20 & 0.91 & 0.44 \\
\hline MRI & 0.83 & 0.85 & -3.1 & 12.2 & 0.31 & 0.04 & 0.93 & 0.18 & 0.99 & 0.53 \\
\hline NCAR & 0.72 & 0.69 & 11.9 & -2.9 & 0.04 & 0.03 & 0.45 & 0.35 & 0.97 & 0.50 \\
\hline
\end{tabular}

(Hesthaven et al. 2007). In particular, the phase lag $\Delta t$ between the two signals $M(t)$ and $S(t)$, sampled at discrete time points $t_{n}, n=1,2, \ldots, N$, where $N=8$, is computed as the time lag that maximizes the cross correlation of the two signals. To compute the cross correlation, we first subtract the mean values from each signal to have two signals $m\left(t_{n}\right)$ and $s\left(t_{n}\right)$ with zero mean; that is,

$m\left(t_{n}\right)=M\left(t_{n}\right)-\frac{1}{N} \sum_{n=1}^{N} M\left(t_{n}\right), \quad s\left(t_{n}\right)=S\left(t_{n}\right)-\frac{1}{N} \sum_{n=1}^{N} S\left(t_{n}\right)$

The cross correlation is expressed as

$$
C(\Delta t) \equiv \frac{\sum_{n=1}^{N} s\left(t_{n}\right) m\left(t_{n}+\Delta t\right)}{\sqrt{\sum_{n=1}^{N} s\left(t_{n}\right)^{2}} \sqrt{\sum_{n=1}^{N} m\left(t_{n}+\Delta t\right)^{2}}},
$$

where the continuous function $m(t)$ is given by the spectral interpolation:

$$
\begin{aligned}
m(t) & \equiv \frac{1}{N} \sum_{k=0}^{N-1} \tilde{m}_{k} e^{-2 \pi i k t / T}, \quad \tilde{m}_{k}=\sum_{n=1}^{N} m\left(t_{n}\right) e^{2 \pi i k t_{n} / T}, \\
k & =0,1, \ldots, N-1,
\end{aligned}
$$

where $T=24 \mathrm{~h}$ is the period of the diurnal cycle. The phase lag is computed by maximizing $C(\Delta t)$ in Eq. (2). Positive (negative) phase-lag value means the modeled
pIWP maximum occurs after (before) the SMILESobserved pIWP peak.

Over land (Fig. 4, middle-left panel), three climate models-CCCma, MIROC, and MOHC-have the smallest $(<1 \mathrm{~h})$ phase lags relative to the SMILES observations; the simulated pIWPs from MERRA reanalysis, IPSL, and MRI models reach their maxima about $2-3 \mathrm{~h}$ before the observation, while BCC-CSM1.1, BCCCSM1.1m, GFDL, GISS, and NCAR models all have phase lags larger than $4 \mathrm{~h}$ before or after the observed maximum. Over ocean (Fig. 4, middle-right panel), the GISS model has the small $(<2 \mathrm{~h})$ phase lags. MERRA, MOHC, and NCAR have phase lags about 3-4 h after the observed maximum. All other models have large phase lags greater than $6 \mathrm{~h}$.

The bottom panels of Fig. 4 show the pIWP diurnal variation amplitude (also see diurnal cycle amplitude column in Table 2), which measures the variation using the standard deviation of the pIWPs sampled at eight different LSTs, normalized by the pIWP mean states, over land and ocean. Over land (Fig. 4, bottom-left panel), models that have diurnal cycle amplitudes close to the observation ( $<10 \%$ difference) are CCCma, MOHC, and MRI, followed by IPSL and MIROC models that have differences within $25 \%$. The two BCC models and the NCAR model have too small amplitudes, being between about $1 / 2$ and $1 / 5$ of the observed value, while GFDL and GISS have too large amplitudes, being about 2 and 3 times the observed value, respectively. Over oceans (Fig. 4, bottom-right panel), most models have the amplitudes close to observations ( $\leq 30 \%$ difference), except 
MIROC and NCAR that have too small amplitudes (about $1 / 3$ and $1 / 4$ of the observed) and GFDL has too large amplitudes (more than 7 times the observed).

\section{d. Quantitative model performance evaluation 2: EOF analysis}

To facilitate a quantitative comparison of the diurnal cycle differences between the SMILES observations and the model simulations, we use the empirical orthogonal function (EOF) analysis (Lorenz 1956) to study the behavior of the diurnal variations. The EOF analysis, which has been used previously to study diurnal cycle of precipitation (e.g. Yang and Slingo 2001; Nesbitt and Zipser 2003; Bowman et al. 2005; Kikuchi and Wang 2008), is useful to identify dominant signals and describe respectively spatial and temporal variations in the data. The diurnal cycle of pIWP is computed as

$D$ pIWP $\left(\right.$ lon, lat,$\left.t_{n}\right)=\operatorname{pIWP}\left(\right.$ lon, lat,$\left.t_{n}\right)-\overline{\mathrm{pIWP}}($ lon, lat $)$,

where pIWP (lon, lat, $t_{n}$ ) is the 6-month-averaged (from 21 October 2009 to 21 April 2010) pIWP in a grid box at a longitude and latitude) and time $t_{n}$ (LST), and the "daily" average, $\overline{\mathrm{pIWP}}(\mathrm{lon}$, lat), is given by

$$
\overline{\mathrm{pIWP}}(\text { lon, lat })=\frac{1}{N} \sum_{n=1}^{N} \operatorname{pIWP}\left(\text { lon, lat }, t_{n}\right),
$$

where $N=8$ is the total number of 3-h LST bins. Using EOF analysis, $D$ pIWP can be expressed as

$$
D \operatorname{pIWP}\left(\text { lon, lat, } t_{n}\right)=\sum_{m} P_{m}(\text { lon }, \text { lat }) V_{m}\left(t_{n}\right),
$$

where $P_{m}$ and $V_{m}$, represent spatial pattern and temporal variation, respectively, for the $m$ th EOF mode. Because the mean state has been subtracted for each $t$ before the EOF analysis, the covariance matrix has rank of 7; that is, there are total seven EOF modes with $m=1,2, \ldots, 7$.

For quantitative model evaluation, we also compute the spatial and temporal variation pattern similarities between the models and observation. The spatial pattern similarity for the first EOF mode is computed by the inner product of the patterns; that is,

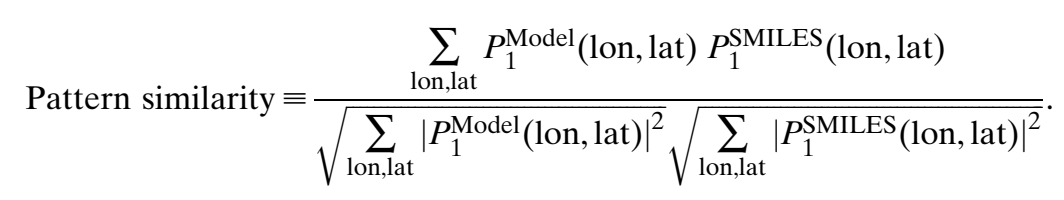

It is a measure of how similar the modeled pIWP spatial distribution is to the SMILES observation. A perfect match has the pattern similarity value equal to 1 , which means the model is $100 \%$ identical to the SMILES observation. Unlike spatial correlation, the spatial pattern similarity computed using Eq. (7) also includes information about the spatial mean in comparing the patterns differences between the model and observation.

The temporal pattern similarity is computed as the maximum value of cross correlation between the model and observation defined by Eq. (2). Here, $s\left(t_{n}\right)$ and $m\left(t_{n}\right)$ are computed from the first EOF mode instead of the mean pIWP. It is a measure of how similar the modeled pIWP temporal variation pattern is to the observation, in addition to the phase lag and amplitude. A perfect match in temporal pattern similarity also has a value of 1 .

The results of EOF analysis between $40^{\circ} \mathrm{S}$ and $40^{\circ} \mathrm{N}$ are shown in Fig. 5 for over land and Fig. 6 for over ocean, in which the first column from the left shows the two leading EOF modes of the $40^{\circ} \mathrm{S}-40^{\circ} \mathrm{N}$ pIWP from
SMILES observations, MERRA reanalysis, and the nine climate models. The maps on the right show the corresponding spatial distributions of the two leading EOF modes.

\section{1) OVER LAND}

Our calculations show that for SMILES observations, the first EOF mode explains $71.4 \%$ of the variance, while second EOF mode explains $11.6 \%$ of the variance. For MERRA reanalysis and most of the climate models, the first EOF modes dominate all the modes, explaining more than $80 \%$ of the variances. One exception is the NCAR model - its first and second EOF modes explain $49.3 \%$ and $25.2 \%$ of the total variance, respectively. The diurnal variation maxima and minima of the first EOF modes (Fig. 5, first column) are located at the same LSTs as those of the mean values shown in Fig. 3, suggesting the diurnal cycles of the mean pIWPs over land are dominated by the first modes.

The maps of the first EOF modes over land from SMILES observation, MERRA reanalysis, and climate models are all similar, showing a positive sign over 

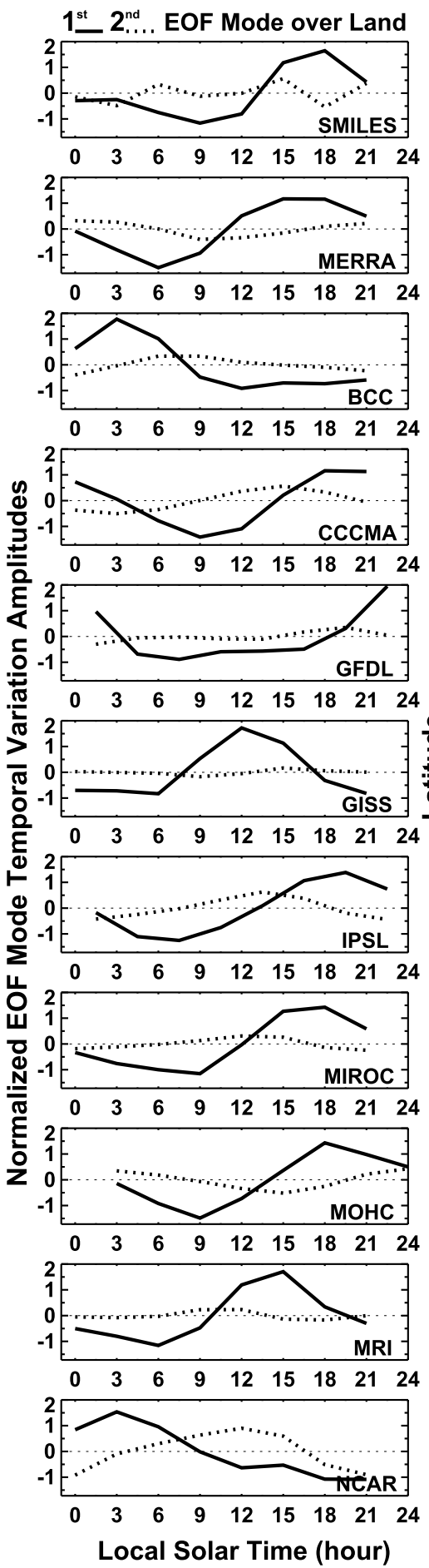

$1^{\text {st }}$ Mode variance explainied: $71.4 \% 2^{\text {nd }}$ Mode variance explainied: $11.6 \%$

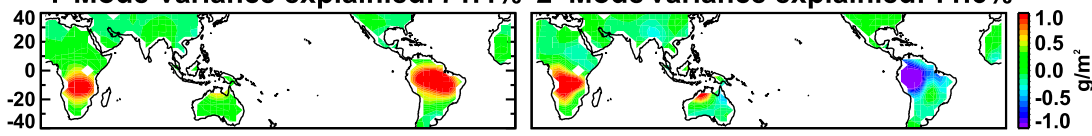

$1^{\text {st }}$ Mode variance explainied: $90.0 \% \quad 2^{\text {nd }}$ Mode variance explainied: $6.9 \%$

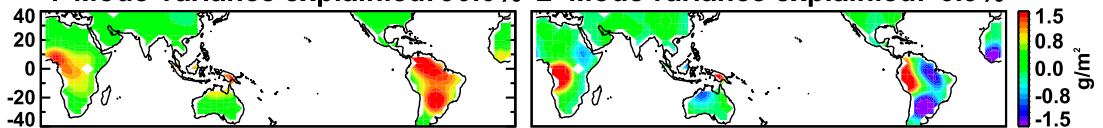

$1^{\text {st }}$ Mode variance explainied: $91.9 \% 2^{\text {nd }}$ Mode variance explainied: $6.0 \%$

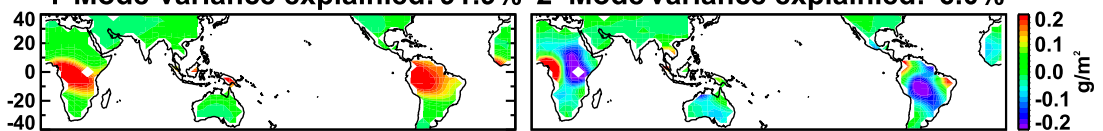

$1^{\text {st }}$ Mode variance explainied: $85.8 \% 2^{\text {nd }}$ Mode variance explainied: $13.2 \%$

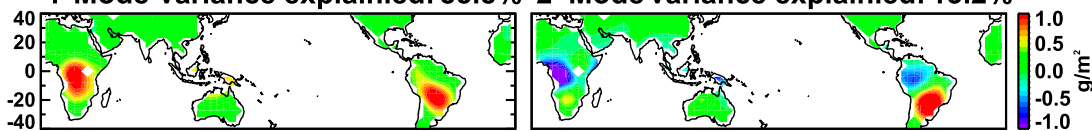

$1^{\text {st }}$ Mode variance explainied: $93.1 \% 2^{\text {nd }}$ Mode variance explainied: $3.6 \%$

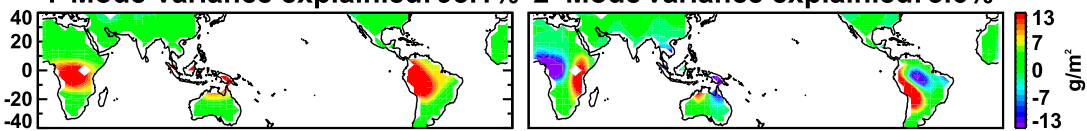

$1^{\text {st }}$ Mode variance explainied: $98.7 \% 2^{\text {nd }}$ Mode variance explainied: $0.9 \%$

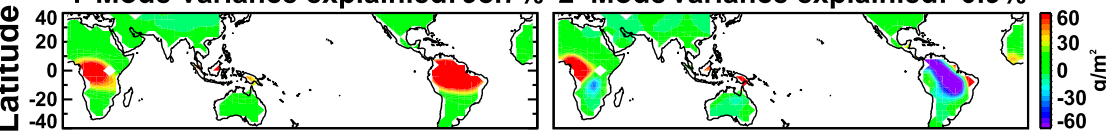

$1^{\text {st }}$ Mode variance explainied: $84.0 \% \quad 2^{\text {nd }}$ Mode variance explainied: $13.3 \%$

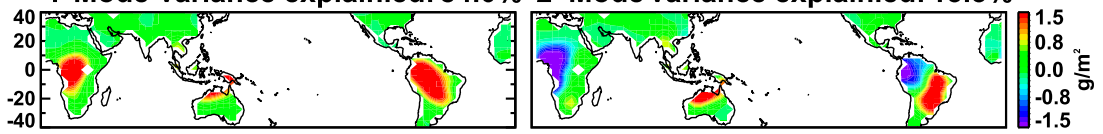

$1^{\text {st }}$ Mode variance explainied: $94.3 \% 2^{\text {nd }}$ Mode variance explainied: $4.1 \%$

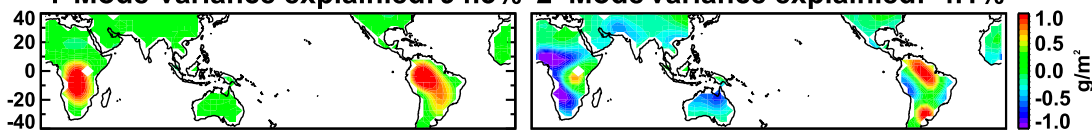

$1^{\text {st }}$ Mode variance explainied: $88.0 \% 2^{\text {nd }}$ Mode variance explainied: $10.5 \%$

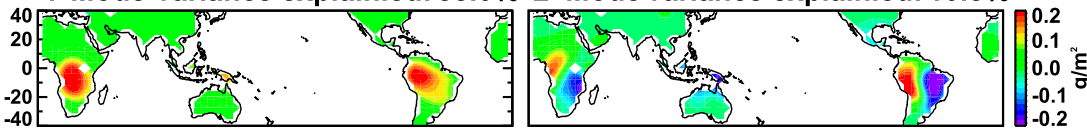

$1^{\text {st }}$ Mode variance explainied: $96.7 \% 2^{\text {nd }}$ Mode variance explainied: $2.3 \%$

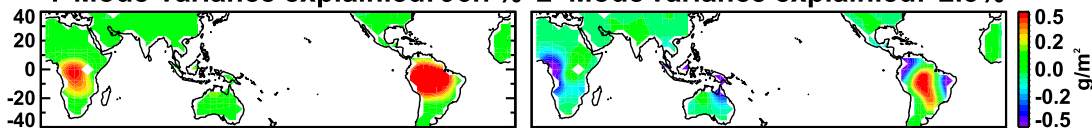

$1^{\text {st }}$ Mode variance explainied: $49.3 \% 2^{\text {nd }}$ Mode variance explainied: $25.2 \%$

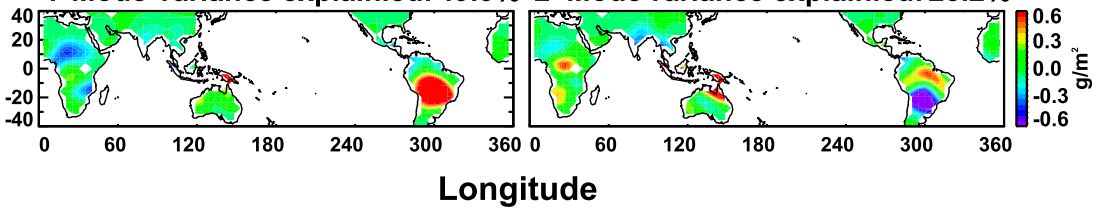

FIG. 5. EOF analysis of diurnal variability over land. (left) Curves of first and second EOF modes are illustrated. (middle),(right) Spatial patterns of the two EOF modes. Percentages of the diurnal variances explained by each mode are marked for SMILES, MERRA reanalysis, and all climate models.

almost all land areas with large values over deep convective regions such as equatorial Africa, South America, and northern Australia. One exception is the NCAR model, which shows a negative value over Africa, South
Asia, and the northern tip of South America, indicating that the diurnal variations in these regions are out of phase by $180^{\circ}$ relative to the variations for the rest of the land. The spatial and temporal pattern similarities of the 


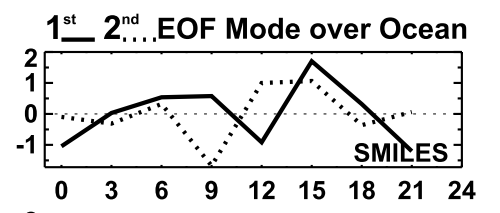

$1^{\text {st }}$ Mode variance explainied: $26.4 \% 2^{\text {nd }}$ Mode variance explainied: $19.9 \%$

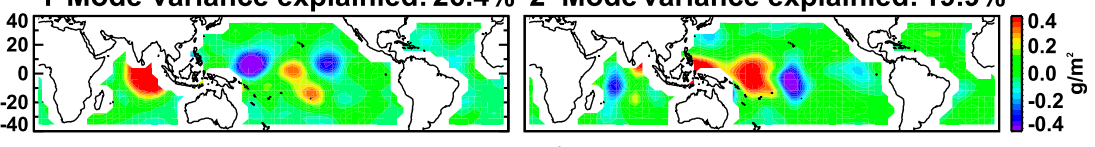

$1^{\text {st }}$ Mode variance explainied: $93.6 \% 2{ }^{\text {nd }}$ Mode variance explainied: $4.9 \%$
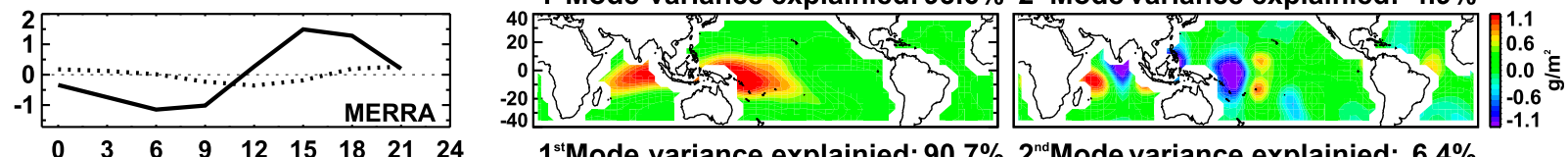

$1^{\text {st }}$ Mode variance explainied: $90.7 \% \quad 2^{\text {nd }}$ Mode variance explainied: $6.4 \%$
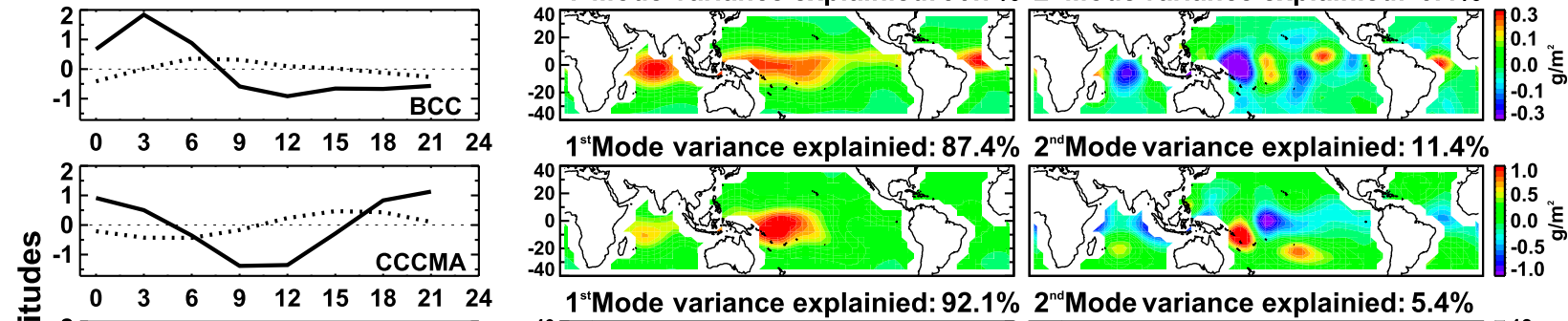

$1^{\text {st }}$ Mode variance explainied: $87.4 \% 2^{\text {nd }}$ Mode variance explainied: $11.4 \%$

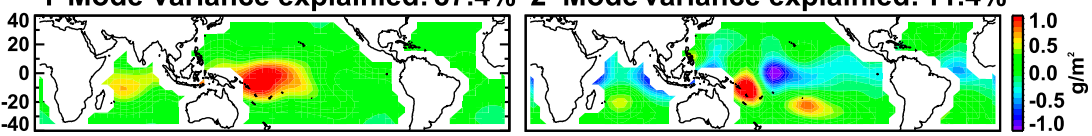

$1^{\text {st }}$ Mode variance explainied: $92.1 \% 2^{\text {nd }}$ Mode variance explainied: $5.4 \%$

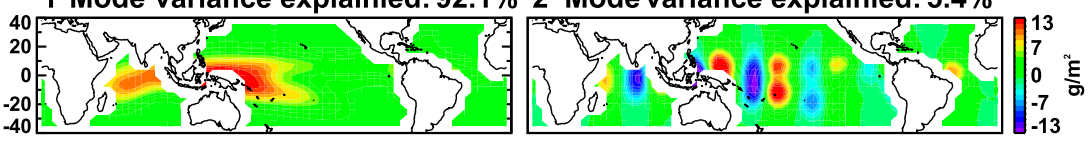

$1^{\text {st }}$ Mode variance explainied: $83.1 \% 2^{\text {nd }}$ Mode variance explainied: $13.3 \%$

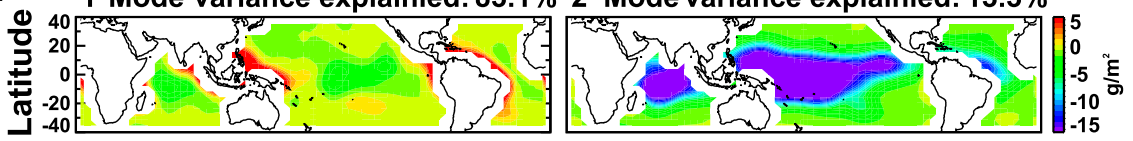

$1^{\text {st }}$ Mode variance explainied: $76.8 \% 2^{\text {nd }}$ Mode variance explainied: $17.2 \%$

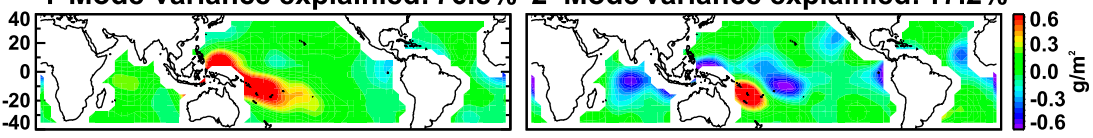

$1^{\text {st }}$ Mode variance explainied: $74.7 \% 2^{\text {nd }}$ Mode variance explainied: $14.1 \%$

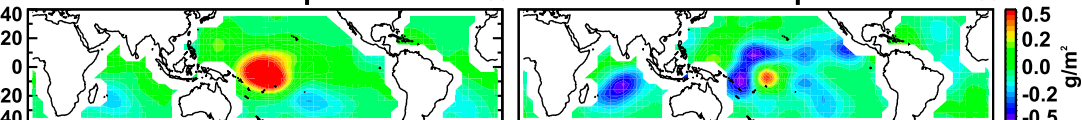

$1^{\text {st }}$ Mode variance explainied: $87.1 \% 2^{\text {nd }}$ Mode variance explainied: $9.4 \%$

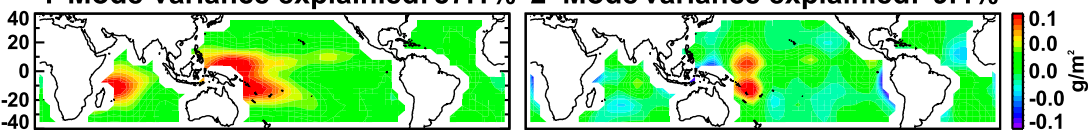

$1^{\text {st }}$ Mode variance explainied: $60.4 \% 2^{\text {nd }}$ Mode variance explainied: $26.4 \%$

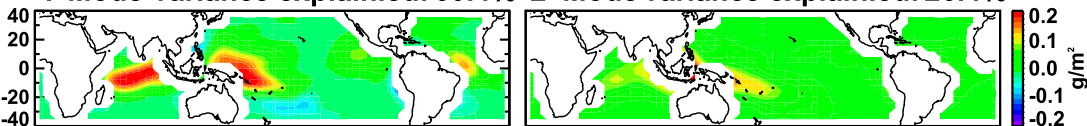

$1^{\text {st }}$ Mode variance explainied: $36.7 \% 2^{\text {nd }}$ Mode variance explainied: $32.6 \%$

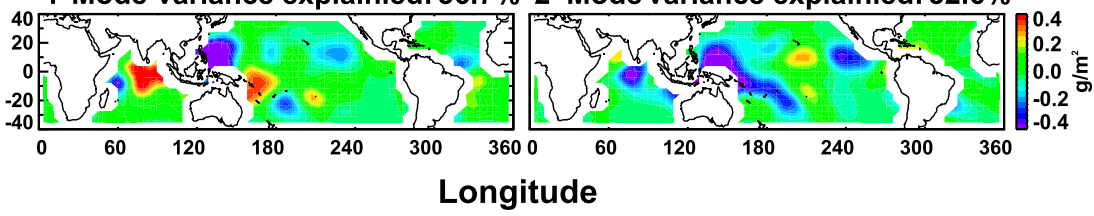

FIG. 6. As in Fig. 4, but for over ocean.

first EOF model are listed in Table 2 and also illustrated in Fig. 7, which shows that the first EOF mode over land from all models has a spatial pattern similarity of 0.7 or greater and a temporal pattern similarity of 0.87 or greater except for the spatial pattern of NCAR model, whose pattern similarity is only 0.45 . The high spatial pattern similarity between observation and models indicates that most of the observed and modeled diurnal variances over land are related to the convective events over central Africa and South America, even though 

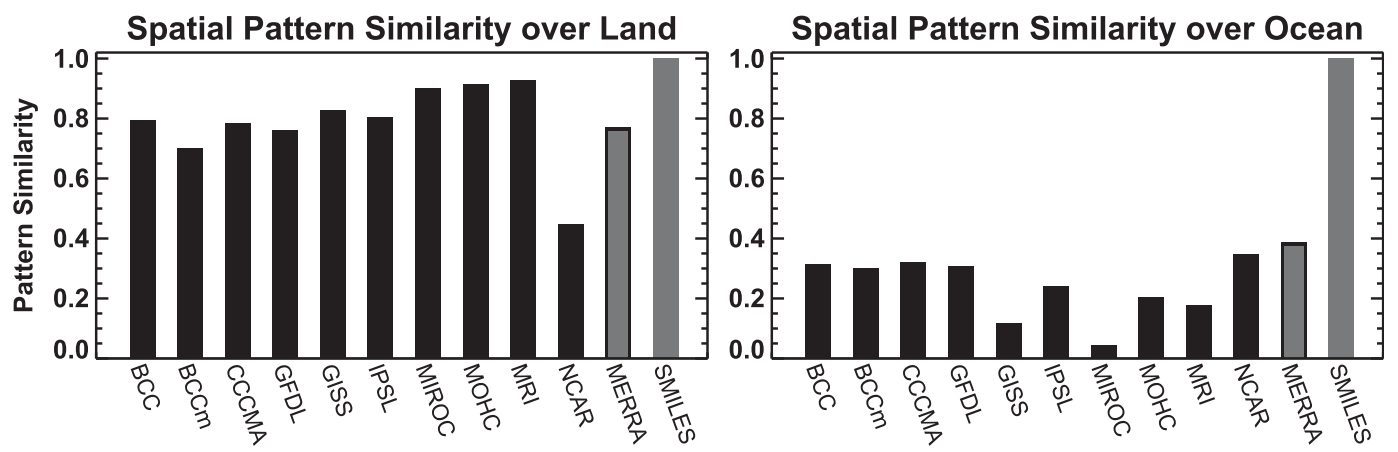

Temporal Pattern Similarity over Land

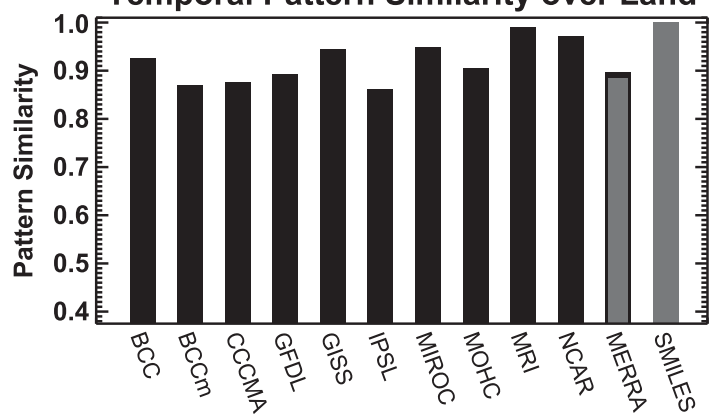

Temporal Pattern Similarity over Ocean

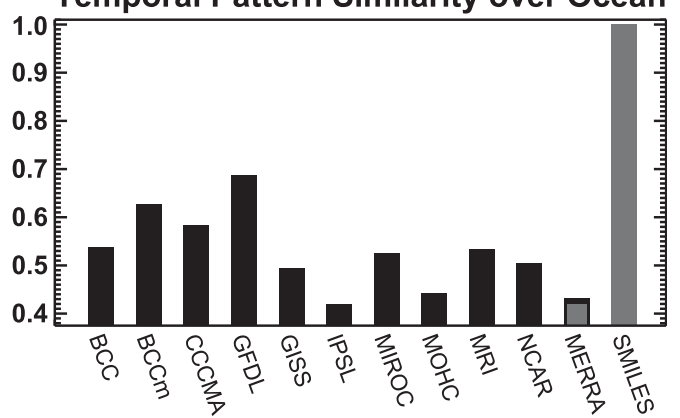

FIG. 7. Model-observation comparison of (top) spatial and (bottom) temporal pattern similarities of first EOF modes over (left) land and (right) ocean.

some models have trouble in correctly simulating the diurnal variation phase and amplitude.

In contrast, the second mode shows high spatial variations and large model-observation and model-model differences. The second EOF mode from SMILES observations shows an east-west dipole pattern with a positive in Africa and negative in South America. MERRA, BCC, GISS, MIROC, and MRI models show somewhat similar dipole patterns (the opposite dipole pattern with negative in Africa and positive in South America is considered similar because the EOF does not fully determine the overall sign of the patterns). Also, CCCma, IPSL, and NCAR (with opposite sign) models show south-north dipole patterns over South America with positive in the south and negative in the north and a negative maximum in Africa, different from SMILES observation. It should be noted that most of these second modes have much smaller contributions than those of the first modes to the total diurnal cycle variance: $10 \%-13 \%$ for SMILES, CCCma, IPSL, and MOHC and 1\%-7\% for MERRA, BCC, GFDL, GISS, MIROC, and MRI. The exception is the NCAR model, whose second mode contributes $25.2 \%$. These differences may indicate that many processes could contribute to the UT ice cloud diurnal cycle and models have difficulty in representing all the physical processes; however, it is not clear which processes the second mode signifies and why models fail to capture them.

\section{2) OVER OCEAN}

The oceanic $D$ pIWP diurnal variation appears more complicated and diverse than that over land. For the SMILES observations, the first and second EOF modes explain only $26.4 \%$ and $19.9 \%$ of the total variance, respectively. However, the model-simulated mean $D$ pIWPs show a large spread on how much the diurnal variances are explained by the first EOF mode. The first EOF modes of DpIWP simulated by MERRA, BCC, CCCma, GFDL, GISS, IPSL, MIROC, and MOHC explain more than $70 \%$ of the diurnal variances, while MRI and NCAR's first modes explain $60.4 \%$ and $36.7 \%$ of the diurnal variances, respectively, and their second modes explain $26.4 \%$ and $32.6 \%$, respectively.

Moreover, for the SMILES observation, the maxima and minima of the first EOF modes (Fig. 6, left column) occur at different LSTs comparing to that of the mean values shown in Fig. 3. This is because the diurnal cycle of the mean pIWP is not only dominated by the first mode, but the second and higher modes may also have strong influences. For MERRA and all climate models except GISS, the diurnal variation maxima and minima of their first EOF modes are located at same LSTs as those of the mean values shown in Fig. 3, suggesting the oceanic pIWP diurnal cycles in the models are dominated by the first modes. For GISS, the first mode is dominated by highly varying pIWP in coastal regions. 
Both its first and second modes contribute significantly to the mean pIWP; thus, it is less obvious how to relate the diurnal cycle of the mean values to the temporal variations of the first and second EOF modes.

Unlike over land, the maps of first EOF mode over ocean show large differences between the observation and models, as well as among different models. For example, SMILES observations show positive values in the Indian Ocean and open waters in the central Pacific and two negative regions north of the equator in the central Pacific. MERRA and most models, however, show a rather similar pattern in their first EOF modes with almost all regions having positive values and peaks from the Indian Ocean to the western Pacific. The exception is the NCAR model: it has relatively larger spatial variation with positive near coastal regions and negative in open oceans. Some other differences can be seen among models as well: MERRA, BCC, CCCma, GFDL, and MRI models have large positive values in a wide region across the Indian Ocean to the western Pacific, while IPSL has a localized maximum in the western Pacific extending to the northeast of Australia, MIROC has a maximum over central Pacific, and MOHC has two separated positive values distributed over the western Indian Ocean and western Pacific. The low first EOF mode pattern similarities over ocean between the models and observations and the relatively large spread among the models can be further illustrated in Fig. 7: no model has spatial pattern similarity larger than 0.4 and temporal pattern similarity larger than 0.7 . As is the case over land, the second EOF mode over ocean also shows higher spatial variations among the models and large model-observation differences.

The discrepancy between modeled results and the observations and the spread of patterns of the leading EOF modes further highlight that the physical mechanisms behind the diurnal cycle of oceanic convective clouds are poorly understood and thus are not properly simulated by the models.

\section{e. Discussion}

It is worth noting that GCMs do not directly "compute" diurnal cycles of clouds. The diurnal cycle of ice clouds, especially over the tropics, is mostly determined by the diurnal cycle of moist convection that is parameterized based on thermodynamic and dynamic environmental conditions, which inherently have diurnal variabilities.

For the BCC model, we note that the better-spatialresolution BCC-CSM1.1m appears to improve only the mean-state ice cloud simulation but not its diurnal cycle representation. The diurnal cycle bias for the BCC model is possibly related to the closure assumption in the deep convective scheme of $\mathrm{Wu}$ (2012), in which stabilization of the atmosphere by convection is in quasi equilibrium with destabilization by large-scale forcing in the troposphere. That is, in the BCC model, the intensity of convection may be largely determined by large-scale environment. This issue is under investigation by the BCC team.

For the CCCma model, since the pIWP is dependent both on the cloud fraction and the cloud-mean IWC, future work by the team will investigate if the variation in their modeled pIWP is mainly from the cloud fraction diurnal cycle or the IWC diurnal cycle, as different model physics is involved in respective calculations.

For the GFDL model, the delay in the time of maximum pIWP relative to SMILES in the GFDL model and the similarity of this time over land and ocean (Fig. 3) are likely related to the closure for deep cumulus convection described by Benedict et al. (2013). By removing contributions to changes in CAPE related to the planetary boundary layer, this closure is not tied strongly to changes in surface temperature, which diurnally vary considerably more over land than ocean. The closure is also particularly sensitive to radiative cooling in the middle and upper troposphere, which is most pronounced at night. The GFDL team noted that the closure used in a different GFDL model version, described by Donner et al. (2011), shows stronger differences in the phases of its diurnal cycle over land and ocean, with the land pIWP maximum occurring as solar insolation heats the surface from 0600 to 0900 LST (not shown; L. Donner 2014, personal communication).

For the GISS model, there are two weaknesses that may cause it to have convection too early during the day: 1) The convective entrainment is too weak, so the model onsets deep convection too soon when it should be making shallow convection (Del Genio et al. 2012). 2) There is a limit placed on the cumulus mass flux in the model to prevent it from getting too large. This affects triggering of deep convection early in the day. These two problems have been partially fixed in the GISS's postCMIP5 model version (Stanfield et al. 2014) by increasing the entrainment rate and removing the mass flux limit (Kim et al. 2012; Del Genio et al. 2012). The newer post-CMIP5 model now has precipitation peaks around 1300-1400 LST, better than the CMIP5 model but not yet as delayed as the observed (A. Del Genio 2014, personal communication).

For the IPSL model, the CM5A-LR version is used in this study. Improvements have been made in a newer ICM5B-LR version, which includes many developments to simulate a better diurnal cycle of convective precipitation over land (Rio et al. 2009).

For MIROC5, it has been suggested that the $e$-folding time of the convective instability (controlled by the 
entrainment rate) and degree of convective selforganization are the possible causes for its diurnal cycle biases over land (M. Watanabe 2014, personal communication). However, it is not obvious how the convection scheme determines the phase of oceanic diurnal cycle.

For MOHC, the diurnal cycle of ice clouds is tied to the diurnal cycle of convection. Yang and Slingo (2001) noted the diurnal cycle was not well simulated in the previous HadAM3 that participated in CMIP3. The current HadGEM2 version for CMIP5 has not been significantly improved. There has been a recent work by Stratton and Stirling (2012) to improve the diurnal cycle of convection in the MOHC models. Their version is between HadGEM2 and the newer post-CMIP5 GA3 version but has not yet been included in any official configuration. The MOHC underestimate of mean-state pIWP is consistent with the results reported by Delanoë et al. (2011). The simulated pIWP diurnal cycle amplitude compares well with the observation; however, Morcrette et al. (2011) noted that the same model tended to overestimate diurnal cycle amplitude of ice cloud fraction.

For the MRI model, the peak of the pIWP diurnal cycle over the land occurs earlier than the observations. It is partly related to the early onset of precipitation diurnal cycle peak in the model's convection scheme, which is a common problem for many convection schemes. In addition, it could also be partly contributed by too quick dissipation of detrained anvil ice clouds in the model by evaporation, fallout, or conversion to snow.

The NCAR model has very weak diurnal cycle. It has multiple EOF modes that are comparable in explained variance over ocean, similar to observations, but the diurnal cycle over land reaches its peak value too early. Speculative explanations for this are a combination of 1) not treating convective inhibition properly and 2) a lack of convective organization and propagation because the current diagnostic mass flux deep convective scheme does not have any "memory" from time step to time step.

It is also possible that some models might capture the diurnal cycle correctly but for the wrong reasons because they do not include all the necessary physical processes responsible for it. Nevertheless, this comparison of model simulations with observations in diurnal cycle of ice clouds challenges model representations of convective processes and thus provides important information for future model improvements, especially for convective parameterizations in the climate models.

\section{Summary}

In this study, we present the diurnal cycles of UT ice clouds in tropical and midlatitudes $\left(40^{\circ} \mathrm{S}-40^{\circ} \mathrm{N}\right)$ from the SMILES pIWP data. The SMILES observations show that the diurnal cycle of UT ice clouds has a clear landocean contrast. Over land, the diurnal variation of pIWP is strong and its maximum occurs between late afternoon and early evening ( $\sim 1800$ LST). Over ocean, the diurnal variation of oceanic pIWP is relatively weak and has two peaks with one at noon and one in the early morning ( $~ 0600$ LST). The results confirmed the earlier report by Millan et al. (2013), which focused on several targeted regions.

The SMILES observations are used to evaluate the performance of climate models to simulate the ice cloud diurnal variability over land and ocean. The mean-state pIWPs simulated by climate models show a large spread over both land and ocean, which are consistent with previous studies (e.g. Jiang et al. 2012; Li et al. 2005, 2012; Waliser et al. 2009). Analysis of modeled pIWP diurnal cycle phase lags show the simulated pIWP can peak at a wide range of LSTs for over both land and ocean. Most models except the GFDL model show smaller diurnal variation amplitudes over ocean than over land, agreeing with the observations. However, there is a large spread of modeled diurnal amplitudes from $20 \%$ to $300 \%$ of the observed amplitude.

The EOF analysis provides a different perspective to describe the diurnal cycle of UT ice cloud. Over land, the leading EOF mode of pIWP for both observation and model simulations explain most (71\% for SMILES observations and more than $80 \%$ for most of the models, except $49 \%$ for NCAR) of the diurnal variations. The first EOF modes, which exhibit a high spatial pattern similarity between observation and models, correspond to wintertime convective events over central Africa and South America. Over ocean, the first EOF mode from SMILES pIWP explains only $26.4 \%$ of the diurnal variances, while most (seven out nine) models have a dominant first EOF mode explaining more than $70 \%$ of the variances. Also, the spatial patterns of pIWP first EOF modes over ocean show large differences between the observation and models, as well as among different models. This discrepancy between the models and the observation and the large spread among models suggest the physical mechanisms behind the diurnal cycle of oceanic UT ice clouds are more complicated and more poorly simulated by the climate models than over land.

Acknowledgments. The authors appreciate the funding support by the NASA ROSES08-USPI, ROSES12MAP, and ROSES13-NDOA programs. This work was performed at the NASA-sponsored Jet Propulsion Laboratory, California Institute of Technology. We are also very thankful for the support from climate modeling centers across the globe, including BCC, CCCma, GFDL, GISS, IPSL, MIROC, MOHC, MRI, NCAR, and MERRA. 

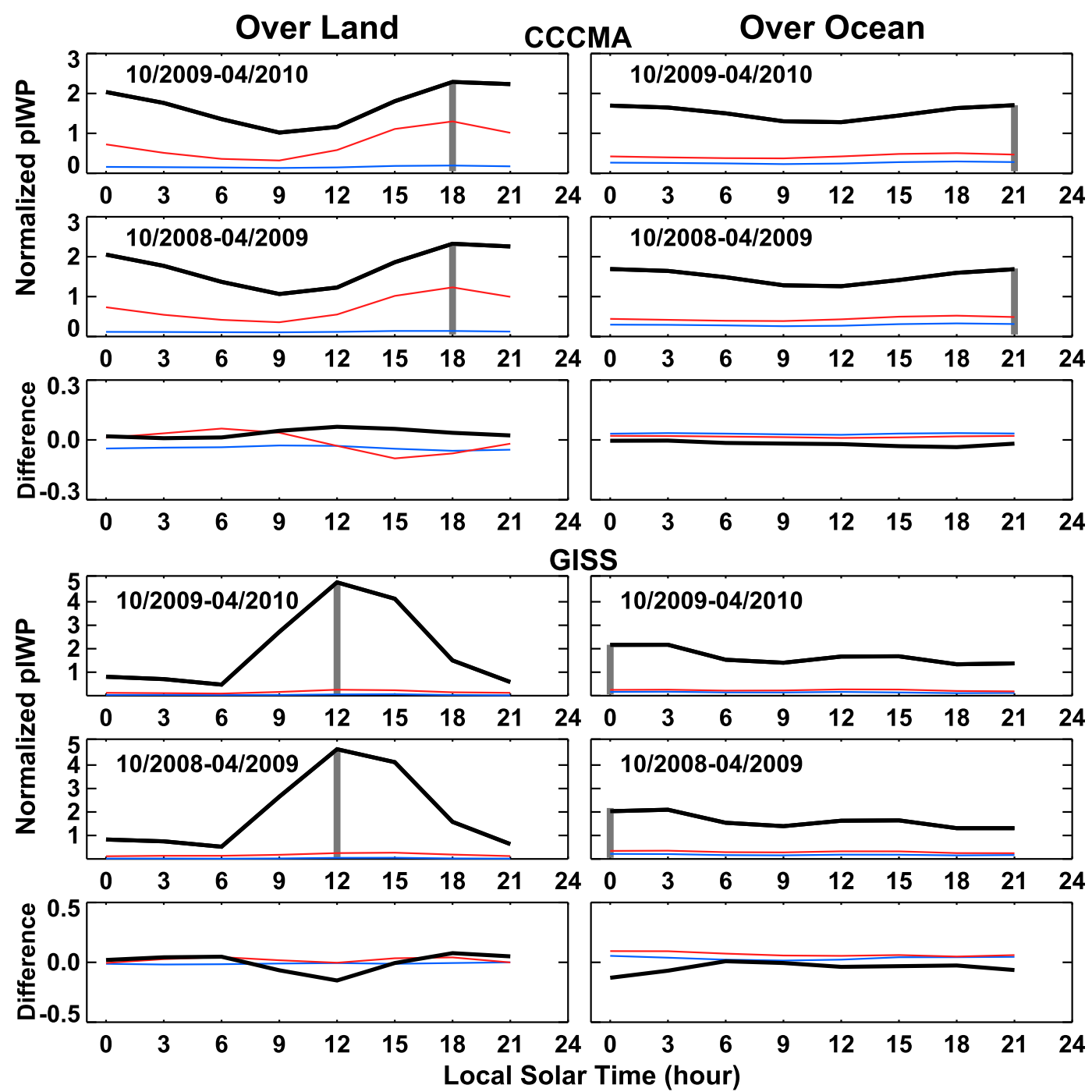

FIG. A1. Diurnal variability of normalized pIWP as simulated by the CCCma CanAM4 and GISS ModelE2 for periods of October 2009-April 2010 and October 2008-April 2009 (indicated in each panel's upper-left corner) as well as the differences between the two periods. Diurnal cycles over (left) land and (right) ocean; colors represent diurnal cycles for tropics (black curve), northern midlatitudes (blue curve), and southern midlatitudes (red curve).

\section{APPENDIX}

\section{Sensitivity Studies}

\section{a. Sensitivity to the interannual variation of pIWP}

In this study, CCCma, GISS, and MIROC models provided 3-hourly simulations during October 2009-April 2010 that exactly match the SMILES observational period. For other models, 3-hourly output of the October-April period was used from the most recent CMIP5 runs. We assume that the interannual variation of modeled pIWP diurnal cycle is small compared to the diurnal variations in any typical year.
The CCCma CanAM4 and the GISS ModelE2 models have provided data for two periods (October 2008-April 2009 and October 2009-April 2010), which allow us to test the interannual changes of diurnal cycles. As illustrated in Fig. A1, we found no change in the diurnal cycle phases and only small changes in diurnal cycle amplitudes $(<2 \%)$ in both CCCma and GISS models and over both land and ocean. The amplitude differences are likely related to the SST variations: there was a strong central Pacific El Niño event during the 2009/10 winter, while the 2008/09 winter was a typical La Niña period. Stronger convection during El Niño is known to generate larger tropical-mean UT IWC (Jiang et al. 2010; Su and 


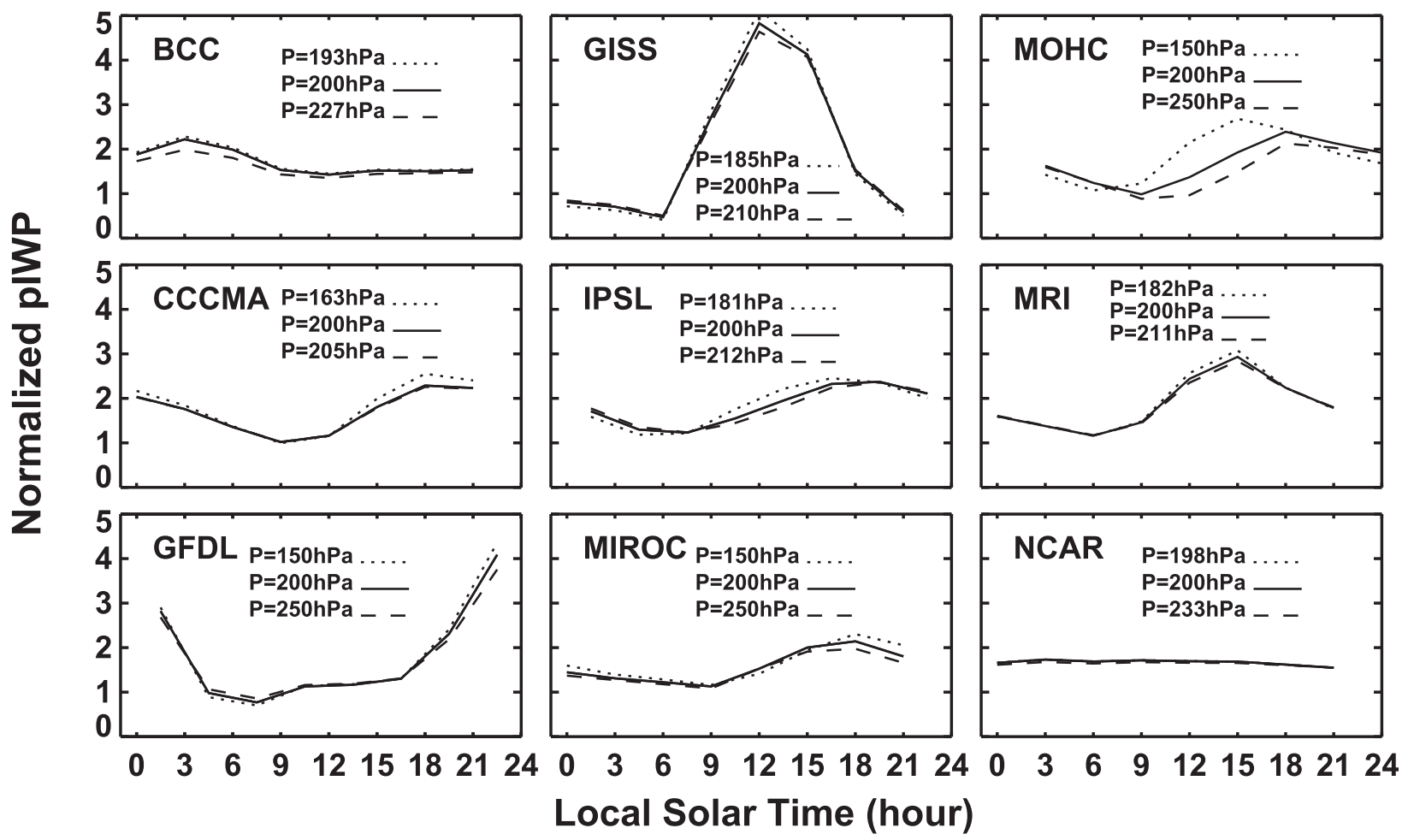

FIG. A2. Comparison of diurnal cycles over land from nine climate models shown by normalized pIWPs integrated from different lowest pressure levels near $200 \mathrm{hPa}$.

Jiang 2013), which might be the cause for a larger diurnal cycle amplitude.

\section{$b$. Sensitivity to the lowest level used in computing the modeled pIWP}

The modeled pIWPs are computed by integrating IWCs at the 200-hPa level and up. Since there may be a strong gradient of ice near $200 \mathrm{hPa}$, the results could be sensitive to the lowest level (highest pressure) used in computing the modeled pIWP. To test this sensitivity, we select one more and one less model level near $200 \mathrm{hPa}$ and repeat the pIWP integration. The choice of the lowest level affects the mean-state pIWP as more (adding one level) or less (removing one level) IWC is used in the pIWP integration. However, as illustrated in Fig. A2, we found the resulting changes of tropical-mean pIWP diurnal cycle phase and amplitude are smallboth over land (Fig. A2) and over ocean (not shown)and will not affect the general conclusion of this study.

\section{c. Comparing SMILES pIWP with pIWPs from Aura $M L S$ and CloudSat}

The SMILES's cloud ice retrieval is based on the established Aura MLS's cloud ice retrieval technique that has been validated and studied in a number of papers (Wu and Jiang 2004; Jiang and Wu 2004; Wu et al. 2006,
2008, 2009; Davis et al. 2005; Jiang et al. 2010). Millan et al. (2013) show comparisons between the monthlymean SMILES data and those from Aura MLS, CloudSat, and CALIPSO and found reasonable agreements. To further validate that differences in retrieval products will not have large impact on our diurnal cycle analysis, we compare SMILES 3-hourly data with the day-night data from Aura MLS and CloudSat, as shown in Fig. A3,

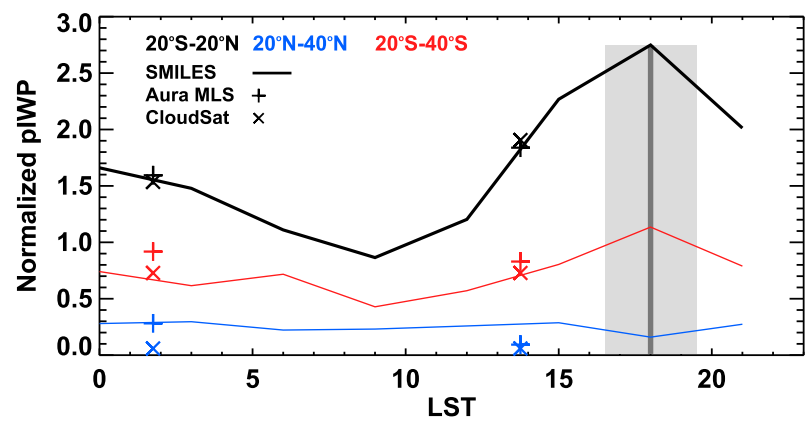

FIG. A3. Diurnal variability of normalized pIWP over land for tropics (black), northern midlatitudes (blue), and southern midlatitudes (red) from SMILES (curves), Aura MLS (+), and CloudSat $(\times)$ retrievals. pIWP is vertically integrated IWC above the $200-\mathrm{hPa}$ pressure level. All values are averaged over the SMILES observational period of October 2009-April 2010 and normalized by the $40^{\circ} \mathrm{S}-40^{\circ} \mathrm{N}$-mean pIWP. 
in which the Aura MLS and CloudSat daytime (0145 LST) and nighttime (1345 LST) pIWPs are computed by vertically integrating the Aura MLS IWCs (version 3.3) and CloudSat IWCs (version R04) above the 200-hPa altitude and averaged over the same SMILES observation period. There is a good agreement between the SMILES, Aura MLS, and CloudSat when diurnal variation is considered, especially in the tropics $\left(20^{\circ} \mathrm{S}-20^{\circ} \mathrm{N}\right)$. The differences in northern $\left(20^{\circ}-40^{\circ} \mathrm{N}\right)$ and southern $\left(20^{\circ}-40^{\circ} \mathrm{S}\right)$ midlatitudes may be due to differences in sampling and sensitivity of different instruments but are within the expected uncertainty range.

\section{REFERENCES}

Albright, M. D., D. R. Mock, E. E. Recker, and R. J. Reed, 1981: A diagnostic study of the diurnal rainfall variation in the GATE B-scale area. J. Atmos. Sci., 38, 1429-1445, doi:10.1175/ 1520-0469(1981)038<1429:ADSOTD>2.0.CO;2.

_ - E. E. Recker, R. J. Reed, and R. Dang, 1985: The diurnal variation of deep convection and inferred precipitation in the central tropical Pacific during January-February 1979. Mon. Wea. Rev., 113, 1663-1680, doi:10.1175/1520-0493(1985)113<1663: TDVODC $>2.0 . \mathrm{CO} ; 2$.

Bechtold, P., J.-P. Chaboureau, A. Beljaars, A. K. Betts, M. Kohler, M. Miller, and J.-L. Redelsperger, 2004: The simulation of the diurnal cycle of convective precipitation over land in a global model. Quart. J. Roy. Meteor. Soc., 130,3119-3137, doi:10.1256/ qj.03.103.

Benedict, J. J., E. D. Maloney, A. H. Sobel, D. M. Frierson, and L. J. Donner, 2013: Tropical intraseasonal variability in version 3 of the GFDL Atmosphere Model. J. Climate, 26, 426449, doi:10.1175/JCLI-D-12-00103.1.

Bowman, K. P., J. C. Collier, G. R. North, Q. Wu, E. Ha, and J. Hardin, 2005: Diurnal cycle of tropical precipitation in Tropical Rainfall Measuring Mission (TRMM) satellite and ocean buoy rain gauge data. J. Geophys. Res., 110, D21104, doi:10.1029/2005JD005763.

Chen, S. S., and R. A. Houze Jr., 1997: Diurnal variation and lifecycle of deep convective systems over the tropical Pacific warm pool. Quart. J. Roy. Meteor. Soc., 123, 357-388, doi:10.1002/ qj. 49712353806 .

Chikira, M., and M. Sugiyama, 2010: A cumulus parameterization with state-dependent entrainment rate. Part I: Description and sensitivity to temperature and humidity profiles. J. Atmos. Sci., 67, 2171-2193, doi:10.1175/2010JAS3316.1.

Collins, W. J., and Coauthors, 2008: Evaluation of the HadGEM2 model. Met Office Hadley Centre Tech. Note 74, 47 pp. [Available online at http://www.metoffice.gov.uk/media/pdf/ 8/7/HCTN_74.pdf.]

Dai, A., and K. E. Trenberth, 2004: The diurnal cycle and its depiction in the Community Climate System Model. J. Climate, 17, 930951, doi:10.1175/1520-0442(2004)017<0930:TDCAID>2.0.CO;2.

— - — , and T. R. Karl, 1999: Effects of clouds, soil moisture, precipitation, and water vapor on diurnal temperature range. J. Climate, 12, 2451-2473, doi:10.1175/1520-0442(1999)012<2451: EOCSMP $>2.0 . \mathrm{CO} ; 2$.

Davis, C. P., D. L. Wu, C. Emde, J. H. Jiang, R. E. Cofield, and R. S. Harwood, 2005: Cirrus induced polarization in $122 \mathrm{GHz}$ Aura Microwave Limb Sounder radiances. Geophys. Res. Lett., 32, L14806, doi:10.1029/2005GL022681.
Delanoë, J., R. J. Hogan, R. M. Forbes, A. Bodas-Salcedo, and T. H. M. Stein, 2011: Evaluation of ice cloud representation in the ECMWF and UK Met Office models using CloudSat and CALIPSO data. Quart. J. Roy. Meteor. Soc., 137, 2064-2078, doi:10.1002/qj.882.

Del Genio, A. D., and J. Wu, 2010: The role of entrainment in the diurnal cycle of continental convection. J. Climate, 23, 27222738, doi:10.1175/2009JCLI3340.1.

—, Y.-H. Chen, D. Kim, and M.-S. Yao, 2012: The MJO transition from shallow to deep convection in CloudSat/CALIPSO data and GISS GCM simulations. J. Climate, 25, 3755-3770, doi:10.1175/JCLI-D-11-00384.1.

Derbyshire, S. H., A. V. Maidens, S. F. Milton, R. A. Stratton, and M. R. Willett, 2011: Adaptive detrainment in a convective parametrization. Quart. J. Roy. Meteor. Soc., 137, 1856-1871, doi:10.1002/qj.875.

Dolinar, E. K., X. Dong, B. Xi, J. H. Jiang, and H. Su, 2015: Evaluation of CMIP5 simulated clouds and TOA radiation budgets using NASA satellite observations. Climate Dyn., doi:10.1007/s00382-014-2158-9, in press.

Donner, L. J., and Coauthors, 2011: The dynamical core, physical parameterizations, and basic simulation characteristics of the atmospheric component AM3 of the GFDL global coupled model CM3. J. Climate, 24, 3484-3519, doi:10.1175/ 2011JCLI3955.1.

Dufresne, J.-L., and Coauthors, 2013: Climate change projections using the IPSL-CM5 Earth System Model: From CMIP3 to CMIP5. Climate Dyn., 40 (9-10), 2123-2165, doi:10.1007/ s00382-012-1636-1.

Feng, Z., X. Dong, B. Xi, C. Schumacher, P. Minnis, and M. Khaiyer, 2011: Top-of-atmosphere radiation budget of convective core/ stratiform rain and anvils from deep convective systems. J. Geophys. Res., 116, D23202, doi:10.1029/2011JD016451.

Gary, W. M., and R. W. Jacobson Jr., 1977: Diurnal variation of deep cumulus convection. Mon. Wea. Rev., 105, 1171-1188, doi:10.1175/1520-0493(1977)105<1171:DVODCC>2.0.CO;2.

Gettelman, A., and Coauthors, 2010: Global simulations of ice nucleation and ice supersaturation with an improved cloud scheme in the Community Atmosphere Model. J. Geophys. Res., 115, D18216, doi:10.1029/2009JD013797.

Gregory, D., and P. R. Rowntree, 1990: A mass flux convection scheme with representation of cloud ensemble characteristics and stability-dependent closure. Mon. Wea. Rev., 118, 1483-1506, doi:10.1175/1520-0493(1990)118<1483:AMFCSW > 2.0.CO;2.

Gregory, J., 1999: Representation of the radiative effects of convective anvils. Hadley Centre Tech. Note 7, 20 pp. [Available online at http://www.metoffice.gov.uk/archive/hadley-centretechnical-note-7.]

Hendon, H. H., and K. Woodberry, 1993: The diurnal cycle of tropical convection. J. Geophys. Res., 98, 16623-16638, doi:10.1029/ 93JD00525.

Hesthaven, J. S., S. Gottlieb, and D. Gottlieb, 2007: Spectral Methods for Time-Dependent Problems. Cambridge University Press, $284 \mathrm{pp}$.

Hourdin, F., and Coauthors, 2013: LMDZ5B: The atmospheric component of the IPSL climate model with revisited parameterizations for clouds and convection. Climate Dyn., 40 (9-10), 2193-2222, doi:10.1007/s00382-012-1343-y.

Houze, R. A., Jr., and A. K. Betts, 1981: Convection in GATE. Rev. Geophys., 19, 541-576, doi:10.1029/RG019i004p00541.

Jiang, J. H., and D. L. Wu, 2004: Ice and water permittivities for millimeter and sub-millimeter remote sensing applications. Atmos. Sci. Lett., 5, 146-151, doi:10.1002/asl.77. 
, and Coauthors, 2010: Five-year (2004-2009) observations of upper tropospheric water vapor and cloud ice from MLS and comparisons with GEOS-5 analyses. J. Geophys. Res., 115, D15103, doi:10.1029/2009JD013256.

_- and Coauthors, 2012: Evaluation of cloud and water vapor simulations in CMIP5 climate models using NASA "A-Train” satellite observations. J. Geophys. Res., 117, D14105, doi:10.1029/ 2011JD017237.

Johnson, R. H., T. M. Rickenbach, S. A. Rutledge, P. E. Ciesielski, and W. H. Schubert, 1999: Trimodal characteristics of tropical convection. J. Climate, 12, 2397-2418, doi:10.1175/ 1520-0442(1999)012<2397:TCOTC > 2.0.CO;2.

Kikuchi, K., and B. Wang, 2008: Diurnal precipitation regimes in the global tropics. J. Climate, 21, 2680-2696, doi:10.1175/ 2007JCLI2051.1.

- , and Coauthors, 2010: Overview and early results of the Superconducting Submillimeter-Wave Limb Emission Sounder (SMILES). J. Geophys. Res., 115, D23306, doi:10.1029/ 2010JD014379.

Kim, D., A. H. Sobel, A. Del Genio, Y.-H. Chen, S. J. Camargo, M.-S. Yao, M. Kelley, and L. Nazarenko, 2012: The tropical subseasonal variability simulated in the NASA GISS general circulation model. J. Climate, 25, 4641-4659, doi:10.1175/ JCLI-D-11-00447.1.

Klein, S. A., Y. Zhang, M. D. Zelinka, R. Pincus, J. Boyle, and P. J. Gleckler, 2013: Are climate model simulations of clouds improving? An evaluation using the ISCCP simulator. J. Geophys. Res. Atmos., 118, 1329-1342, doi:10.1002/jgrd.50141.

Kraus, E. B., 1963: The diurnal precipitation change over the sea. J. Atmos. Sci., 20,551-556, doi:10.1175/1520-0469(1963)020<0551: TDPCOT>2.0.CO;2.

Kuang, Z., and C. S. Bretherton, 2006: A mass flux scheme view of a high-resolution simulation of transition from shallow to deep cumulus convection. J. Atmos. Sci., 63, 1895-1909, doi:10.1175/ JAS3723.1.

Lee, M.-I., and Coauthors, 2007: An analysis of the warm season diurnal cycle over the continental United States and northern Mexico in general circulation models. J. Hydrometeor., 8, 344366, doi:10.1175/JHM581.1.

Li, J.-L., and Coauthors, 2005: Comparisons of EOS MLS cloud ice measurements with ECMWF analyses and GCM simulations: Initial results. Geophys. Res. Lett., 32, L18710, doi:10.1029/ 2005 GL023788.

_ - and Coauthors, 2012: An observationally based evaluation of cloud ice water in CMIP3 and CMIP5 GCMs and contemporary reanalyses using contemporary satellite data. J. Geophys. Res., 117, D16105, doi:10.1029/2012JD017640.

Liu, C., and M. W. Moncrieff, 1998: A numerical study of the diurnal cycle of tropical oceanic convection. J. Atmos. Sci., 55, 2329-2344, doi:10.1175/1520-0469(1998)055<2329:ANSOTD>2.0.CO;2.

Liu, X., and J. E. Penner, 2005: Ice nucleation parameterization for global models. Meteor. Z., 14, 499-514, doi:10.1127/0941-2948/ 2005/0059.

Livesey, N. J., and Coauthors, 2013: Earth Observing System (EOS) Aura Microwave Limb Sounder (MLS) version 2.2 and 2.3 level 2 data quality and description document. Jet Propulsion Laboratory Tech. Rep. JPL D-33509, 118 pp. [Available online at http://mls.jpl.nasa.gov/data/v2_data_quality_document. pdf.]

Lorenz E. N., 1956: Empirical orthogonal functions and statistical weather prediction. Statistical Forecasting Project Sci. Rep. 1, $48 \mathrm{pp}$. [Available online at http://www.o3d.org/abracco/Atlantic/ Lorenz1956.pdf.]
Manabe, T., T. Fukami, T. Nishibori, K. Mizukoshi, and S. Ochiai, 2008: Measurement and evaluation of submillimeter-wave antenna quasioptical feed system by a phase-retrieval method in the $640-\mathrm{GHz}$ band. IEICE Trans. Commun., E91.B, 1760 1766, doi:10.1093/ietcom/e91-b.6.1760.

Mapes, B. E., 2000: Convective inhibition, subgrid-scale triggering energy, and stratiform instability in a toy tropical wave model. J. Atmos. Sci., 57, 1515-1535, doi:10.1175/ 1520-0469(2000)057<1515:CISSTE $>2.0$. CO;2.

May, P. T., C. N. Long, and A. Protat, 2012: The diurnal cycle of the boundary layer, convection, clouds, and surface radiation in a coastal monsoon environment (Darwin, Australia). J. Climate, 25, 5309-5326, doi:10.1175/JCLI-D-11-00538.1.

McGarry, M. M., and R. J. Reed, 1978: Diurnal variations in convective activity and precipitation during phases II and III of GATE. Mon. Wea. Rev., 106, 101, doi:10.1175/1520-0493(1978)106<0101: DVICAA $>2.0 . \mathrm{CO} ; 2$.

Millan, L., and Coauthors, 2013: SMILES ice cloud products. J. Geophys. Res. Atmos., 118, 6468-6477, doi:10.1002/jgrd.50322.

Morcrette, C. J., E. J. O'Connor, and J. C. Petch, 2011: Evaluation of two cloud parametrization schemes using ARM and CloudNet observations. Quart. J. Roy. Meteor. Soc., 138, 964-979, doi:10.1002/qj.969.

Nesbitt, S. W., and E. J. Zipser, 2003: The diurnal cycle of rainfall and convective intensity according to three years of TRMM measurements. J. Climate, 16, 1456-1475, doi:10.1175/ 1520-0442-16.10.1456.

Nitis, T., D. Kitsiou, Z. B. Klaiìc, M. T. Prtenjak, and N. Moussiopoulos, 2005: The effects of basic flow and topography on the development of the sea breeze over a complex coastal environment. Quart. J. Roy. Meteor. Soc., 131, 305-328, doi:10.1256/qj.04.42.

Park, S., and C. S. Bretherton, 2009: The University of Washington shallow convection and moist turbulence schemes and their impact on climate simulations with the community atmosphere model. J. Climate, 22, 3449-3469, doi:10.1175/2008JCLI2557.1.

Pritchard, M. S., and R. C. J. Somerville, 2009: Assessing the diurnal cycle of precipitation in a multi-scale climate model. $J$. $A d v$. Model. Earth Syst., 1, 12, doi:10.3894/JAMES.2009.1.12.

Randall, D. A., Harshvardhan, and D. A. Dazlich, 1991: Diurnal variability of the hydrologic cycle in a general circulation model. J. Atmos. Sci., 48, 40-62, doi:10.1175/1520-0469(1991)048<0040: DVOTHC $>2.0 . \mathrm{CO} ; 2$.

Ray, C. L., 1928: Diurnal variation of rainfall at San Juan, P.R. Mon. Wea. Rev., 56, 140-141, doi:10.1175/1520-0493(1928)56<140: DVORAS $>2.0 . \mathrm{CO} ; 2$.

Reed, R. J., and K. D. Jaffe, 1981: Diurnal variation of summer convection over West Africa and the tropical eastern Atlantic during 1974 and 1978. Mon. Wea. Rev., 109, 2527-2534, doi:10.1175/1520-0493(1981)109<2527:DVOSCO > 2.0.CO;2.

Rio, C., F. Hourdin, J. Y. Grandpeix, and J. P. Lafore, 2009: Shifting the diurnal cycle of parameterized deep convection over land. Geophys. Res. Lett., 36, L07809, doi:10.1029/2008GL036779.

Russell, G. L., J. R. Miller, and D. Rind, 1995: A coupled atmosphereocean model for transient climate change studies. Atmos.Ocean, 33, 683-730, doi:10.1080/07055900.1995.9649550.

Salby, M. L., H. H. Hendon, K. Woodberry, and K. Tanaka, 1991: Analysis of global cloud imagery from multiple satellites. Bull. Amer. Meteor. Soc., 72, 467-480, doi:10.1175/ 1520-0477(1991)072<0467:AOGCIF>2.0.CO;2.

Sato, T., H. Miura, M. Satoh, Y. N. Takayabu, and Y. Wang, 2009: Diurnal cycle of precipitation in the tropics simulated in a global cloud-resolving model. J. Atmos. Sci., 22, 4809-4826, doi:10.1175/2009JCLI2890.1. 
Schmidt, G. A., and Coauthors, 2014: Configuration and assessment of the GISS ModelE2 contributions to the CMIP5 archive. J. Adv. Model. Earth Syst., 6, 141-184, doi:10.1002/ 2013MS000265.

Scinocca, J. F., and N. A. McFarlane, 2013: The variability of modeled tropical precipitation. J. Atmos. Sci., 61, 1993-2015, doi:10.1175/1520-0469(2004)061<1993:TVOMTP>2.0.CO;2.

Slingo, J., P. Inness, R. Neale, S. Woolnough, and G. Yang, 2003: Scale interactions on diurnal to seasonal timescales and their relevance to model systematic errors. Ann. Geophys., 46, doi:10.4401/ag-3383.

Smith, R. N. B., 1990: A scheme for predicting layer cloud and their water content in a general circulation model. Quart. J. Roy. Meteor. Soc., 116, 435-460, doi:10.1002/qj.49711649210.

Soden, B. J., 2000: The diurnal cycle of convection. Geophys. Res. Lett., 27, 2173-2176, doi:10.1029/2000GL011436.

Stanfield, R. E., X. Dong, B. Xi, A. Kennedy, A. D. Del Genio, P. Minis, and J. H. Jiang, 2014: Assessment of NASA GISS CMIP5 and post-CMIP5 simulated clouds and TOA radiation budgets using satellite observations. Part I: Cloud fraction and properties. J. Climate, 27, 4189-4208, doi:10.1175/ JCLI-D-13-00558.1.

Stratton, R. A., and A. J. Stirling, 2012: Improving the diurnal cycle of convection in GCMs. Quart. J. Roy. Meteor. Soc., 138,11211134, doi:10.1002/qj.991.

Stuart-Menteth, A. C., I. S. Robinson, and P. G. Challenor, 2003: A global study of diurnal warming using satellite-derived sea surface temperature. J. Geophys. Res., 108, 3155, doi:10.1029/ $2002 J C 001534$.

Su, H., and J. H. Jiang, 2013: Tropical clouds and circulation changes during the 2006/07 and 2009/10 El Niños. J. Climate, 26, 399-413, doi:10.1175/JCLI-D-12-00152.1.

_, W. G. Read, J. H. Jiang, J. W. Waters, D. L. Wu, and E. J. Fetzer, 2006: Enhanced positive water vapor feedback associated with tropical deep convection: New evidence from Aura MLS. Geophys. Res. Lett., 33, L05709, doi:10.1029/ 2005 GL025505.

, J. H. Jiang, J. Teixeira, A. Gettelman, X. Huang, G. Stephens, D. Vane, and V. S. Perun, 2011: Comparison of regime-sorted tropical cloud profiles observed by CloudSat with GEOS5 analyses and two general circulation model simulations. J. Geophys. Res., 116, D09104, doi:10.1029/2010JD014971.

__ , and Coauthors, 2013: Diagnosis of regime-dependent cloud simulation errors in CMIP5 models using "A-Train" satellite observations and reanalysis data. J. Geophys. Res. Atmos. 118, 2762-2780, doi:10.1029/2012JD018575.

Sui, C.-H., X. Li, and K.-M. Lau, 1998: Radiative-convective processes in simulated diurnal variations of tropical oceanic convection. J. Atmos. Sci., 55, 2345-2357, doi:10.1175/ 1520-0469(1998)055<2345:RCPISD > 2.0.CO;2.

Takemura, T., T. Nozawa, S. Emori, T. Y. Nakajima, and T. Nakajima, 2005: Simulation of climate response to aerosol direct and indirect effects with aerosol transport-radiation model. J. Geophys. Res., 110, D02202, doi:10.1029/2004JD005029.

Taylor, K. E., R. J. Stouffer, and G. A. Meehl, 2012: An overview of CMIP5 and the experiment design. Bull. Amer. Meteor. Soc., 93, 485-498, doi:10.1175/BAMS-D-11-00094.1.

Taylor, P. C., 2012: Tropical outgoing longwave radiation and longwave cloud forcing diurnal cycles from CERES. J. Atmos. Sci., 69, 3652-3669, doi:10.1175/JAS-D-12-088.1.

_ 2014: Variability of monthly diurnal cycle composites of TOA radiative fluxes in the tropics. J. Atmos. Sci., 71, 754-766, doi:10.1175/JAS-D-13-0112.1.
Tian, B., B. J. Soden, and X. Wu, 2004: Diurnal cycle of convection, clouds, and water vapor in the tropical upper troposphere: Satellites versus a general circulation model. J. Geophys. Res., 109, D10101, doi:10.1029/2003JD004117.

, D. E. Waliser, and E. J. Fetzer, 2006: Modulation of the diurnal cycle of tropical deep convective clouds by the MJO. Geophys. Res. Lett., 33, L20704, doi:10.1029/ 2006GL027752.

, E. J. Fetzer, B. H. Kahn, J. Teixeira, E. Manning, and T. Hearty, 2013: Evaluating CMIP5 models using AIRS tropospheric air temperature and specific humidity climatology. J. Geophys. Res. Atmos., 118, 114-134, doi:10.1029/2012JD018607. von Salzen, K., and Coauthors, 2013: The Canadian Fourth Generation Atmospheric Global Climate Model (CanAM4). Part I: Representation of physical processes. Atmos.-Ocean, 51, 104-125, doi:10.1080/07055900.2012.755610.

Waliser, D. E., and Coauthors, 2009: Cloud ice: A climate model challenge with signs and expectations of progress. J. Geophys. Res., 114, D00A21, doi:10.1029/2008JD010015.

Wallace, J. M., 1975: Diurnal variations in precipitation and thunderstorm frequency over the conterminous United States. Mon. Wea. Rev., 103, 406-419, doi:10.1175/1520-0493(1975)103<0406: DVIPAT $>2.0 . \mathrm{CO} ; 2$.

Watanabe, M., S. Emori, M. Satoh, and H. Miura, 2009: A PDF-based hybrid prognostic cloud scheme for general circulation models. Climate Dyn., 33, 795-816, doi:10.1007/s00382-008-0489-0.

— MIROC5: Mean states, variability, and climate sensitivity. J. Climate, 23, 6312-6335, doi:10.1175/2010JCLI3679.1.

Wilson, D. R., and S. P. Ballard, 1999: A microphysically based precipitation scheme for the UK Meteorological Office unified model. Quart. J. Roy. Meteor. Soc., 125, 1607-1636, doi:10.1002/ qj.49712555707.

Wu, D. L., and J. H. Jiang, 2004: EOS MLS algorithm theoretical basis for cloud measurements. Jet Propulsion Laboratory Tech. Doc. JPL D-19299, 128 pp. [Available online at https://mls.jpl. nasa.gov/data/eos_cloud_atbd.pdf.]

- ——, and C. P. Davis, 2006: EOS MLS cloud ice measurements and cloudy-sky radiative transfer model. IEEE Trans. Geosci. Remote Sens., 44, 1156-1165, doi:10.1109/TGRS.2006.869994.

, and Coauthors, 2008: Validation of the Aura MLS cloud ice water content (IWC) measurements. J. Geophys. Res., 113, D15S10, doi:10.1029/2007JD008931.

— , and Coauthors, 2009: Comparisons of global cloud ice from MLS, CloudSat, and correlative data sets. J. Geophys. Res., 114, D00A24, doi:10.1029/2008JD009946.

$\mathrm{Wu}, \mathrm{T} ., 2012$ : A mass-flux cumulus parameterization scheme for large-scale models: Description and test with observations. Climate Dyn., 38, 725-744, doi:10.1007/s00382-011-0995-3.

— , and Coauthors, 2010: The Beijing Climate Center atmospheric general circulation model: Description and its performance for the present-day climate. Climate Dyn., 34, 123147, doi:10.1007/s00382-008-0487-2.

— , and Coauthors, 2013: Global carbon budgets simulated by the Beijing Climate Center Climate System Model for the last century. J. Geophys. Res. Atmos., 118, 4326-4347, doi:10.1002/ jgrd.50320.

Yang, G., and J. Slingo, 2001: The diurnal cycle in the tropics. Mon. Wea. Rev., 129, 784-801, doi:10.1175/1520-0493(2001)129<0784: TDCITT $>2.0 . \mathrm{CO} ; 2$.

Yoshimura, H., R. Mizuta, and H. Murakami, 2015: A spectral cumulus parameterization scheme interpolating between two convective updrafts with semi-Lagrangian calculation of 
transport by compensatory subsidence. Mon. Wea. Rev., 143, 597-621, doi:10.1175/MWR-D-14-00068.1.

Yukimoto, S., and Coauthors, 2011: Meteorological Research Institute Earth System Model Version 1 (MRI-ESM1) model description. Meteorological Research Institute Tech. Rep. 64, 83 pp. [Available online at http://www.mri-jma.go.jp/Publish/ Technical/DATA/VOL_64/index_en.html.]

, and Coauthors, 2012: A new global climate model of Meteorological Research Institute: MRI-CGCM3-Model description and basic performance. J. Meteor. Soc. Japan, 90A, 23-64, doi:10.2151/jmsj.2012-A02.

Zhang, G. J., 2002: Convective quasi-equilibrium in midlatitude continental environment and its effect on convective parameterization. J. Geophys. Res., 107, 4220, doi:10.1029/2001JD001005. , and N. A. McFarlane, 1995: Sensitivity of climate simulations to the parameterization of convection in the Canadian Climate Centre general circulation model. Atmos.-Ocean, 33, 407-446, doi:10.1080/07055900.1995.9649539. 